\title{
Mode mixity analysis of face/core debonds in a single cantilever beam sandwich specimen
}

\section{Saseendran, Vishnu; Berggreen, Christian; Krueger, Ronald}

Published in:

Journal of Sandwich Structures and Materials

Link to article, DOI:

$10.1177 / 1099636218788223$

Publication date:

2020

Document Version

Peer reviewed version

Link back to DTU Orbit

Citation (APA):

Saseendran, V., Berggreen, C., \& Krueger, R. (2020). Mode mixity analysis of face/core debonds in a single cantilever beam sandwich specimen. Journal of Sandwich Structures and Materials, 22(6), 1879-1909. https://doi.org/10.1177/1099636218788223

\section{General rights}

Copyright and moral rights for the publications made accessible in the public portal are retained by the authors and/or other copyright owners and it is a condition of accessing publications that users recognise and abide by the legal requirements associated with these rights.

- Users may download and print one copy of any publication from the public portal for the purpose of private study or research.

- You may not further distribute the material or use it for any profit-making activity or commercial gain

- You may freely distribute the URL identifying the publication in the public portal 


\title{
Mode Mixity Analysis of Face/Core Debonds in a Single Cantilever Beam Sandwich Specimen
}

\author{
Vishnu Saseendran and Christian Berggreen \\ Department of Mechanical Engineering, Technical University of Denmark, Nils Koppels Allé, Building \\ 404, 2800 Kgs. Lyngby, Denmark \\ Ronald Krueger
}

National Institute of Aerospace, 100 Exploration Way, Hampton, VA 23681-2199, USA

\begin{abstract}
$\underline{\text { Abstract }}$
The Single Cantilever Beam (SCB) sandwich specimen has been proposed, as a fracture test standard for mode I peel loading. Critical parameters, including specimen dimensions, determine whether the crack propagates along the face/core interface in mode I during the fracture test. This paper outlines a parametric study based on a numerical method to examine local mode mixity conditions for a wide array of sandwich systems by varying several geometrical and material parameters. The thickness and modulus of the face sheet were seen to influence the mode mixity for most sandwich systems. Core Poisson's ratio was shown to influence the local mode mixity and has the capability of driving the crack along the interface or into the core. The effect of the intact specimen length was analyzed and presented from a mode mixity perspective based on various elastic foundation modulus expressions. Reinforcement of the SCB specimen with stiff layers was also investigated numerically and compared with a similar analysis in the literature. The analysis presented in this paper shows that, despite reducing the global shear component, the local mode mixity condition deviated away from the mode I regime for several sandwich specimens. An appropriate foundation model along with a minimum loading rod length was one of the recommendations provided from the analyses, which may supplement the ASTM International standardization efforts.
\end{abstract}

Keywords: SCB; Sandwich; Debond; Mode mixity; Face/core interface; Phase angle; CSDE

\section{Introduction}

Typical damage modes in sandwich structures include face/core debonding and core crushing; posing a threat to the structural integrity of a component. These damage modes are of particular interest to certification authorities since several in-service occurrences, such as a rudder structural failure [1] and other control surface malfunctions, have been attributed to debonding [2]. Extensive studies have shown that debonding can lead to failure caused by internal pressure changes in the core due to ground-airground (GAG) cycles [1]-[5]. Future composite structure applications including composite sandwich construction of the fuselage of business jets that experience higher altitudes than transport aircraft, are driving a need to understand the phenomenon of debond growth under generalized load scenarios that

\section{Corresponding Author:}

Vishnu Saseendran, Department of Mechanical Engineering,

Technical University of Denmark, Nils Koppels Allé,

Building 404, 2800 Kgs. Lyngby, Denmark

E-mail:vsas@mek.dtu.dk 
include maneuvers and gust conditions. Furthermore, the relevance of this issue extends to spacecraft where large scale face/core debonding were reported [6], [7].

In order to have reliable damage assessment models, the quality of face/core interface strength must be ascertained with a high degree of accuracy. The most critical debonding phenomenon in sandwich composites is likely to be mode I dominated, where the face sheet was peeled away from the core. Thus, the critical strain energy release rate (interface fracture toughness) related to the face/core separation must be estimated using reliable test methods. In a recent study, the suitability of five test methods for measuring debond toughness associated with face/core peel loading was evaluated [8]. A single cantilever beam (SCB) type configuration, initially discussed in [9] and [10], was identified as the most appropriate test (see Figure 1a). This determination was based on the following findings: (1) the test involved a simple loading fixture; (2) debond front conditions were found to be uniform over a range of debond lengths; (3) debonding was found to take place along or near the face/core interface, rather than kinking into the core; (4) the data reduction method used for computing debond toughness involved a straightforward compliance calibration procedure.

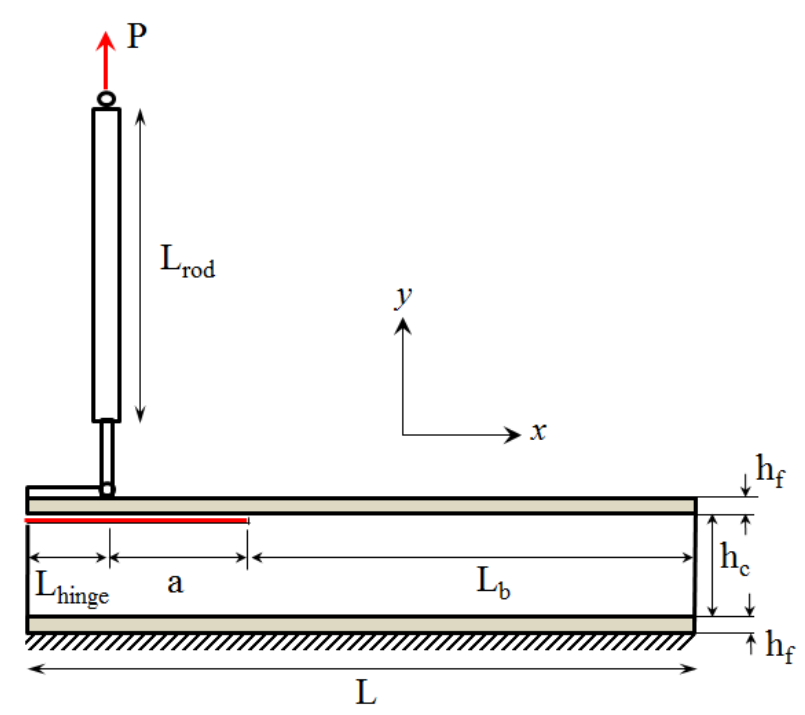

(a)

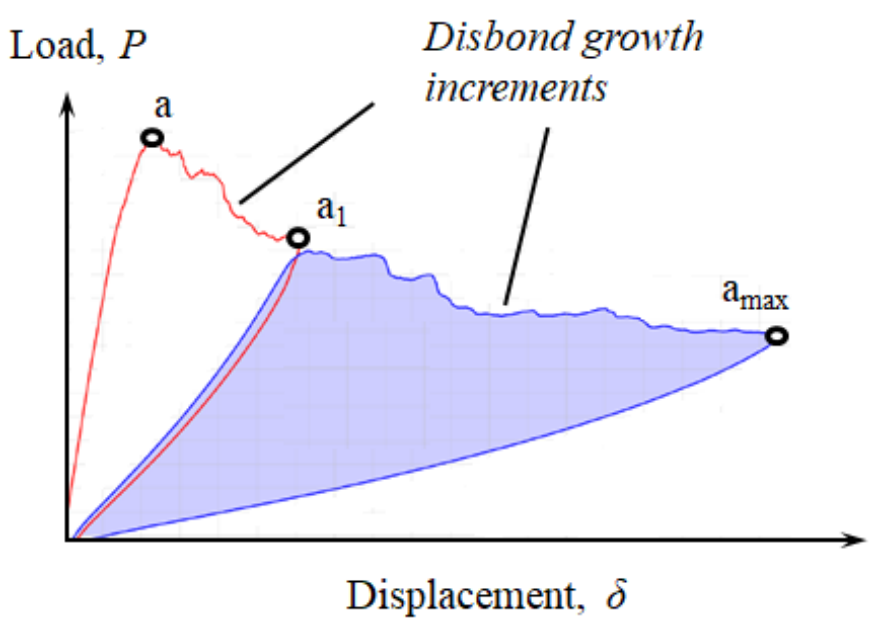

(b)

Figure 1. (a) Schematic illustration of the Single Cantilever Beam (SCB) sandwich specimen (b) typical load-unload curve of a sandwich SCB specimen.

The SCB sandwich specimen (see Figure 1a) with a pre-crack (a) lying close to the upper face sheet was fixed on a rigid base and loaded with a loading rod. The pre-crack is a discontinuity in the interface and is usually created by inserting Teflon ${ }^{\circledR}$ film during the production phase. Pre-cracks have also been introduced using saw-cuts, but all must have a sharp crack front. In the SCB test method, load is applied to the upper debonded face sheet and the bottom face sheet is rigidly fixed. The force is applied through 
a loading rod which is attached to the upper debonded face sheet through a hinge. Both loading rod and hinge ensure that the load application point remains vertical as the debond grows. The test is conducted in displacement control by pulling the debonded face sheet at a constant rate. The specimen is un-loaded when the crack increases to $a_{1}$ (see Figure $1 b$ ). A suitable imaging system is used to ascertain crack position during the test and both displacement and force are continuously recorded during the test. Different methods to reduce energy release data have been proposed for the SCB test: area method, modified beam theory, and compliance calibration method [11]. The latter two methods require a linear force-displacement response of the specimen, which specimens with thin face sheets may not yield. To encompass testing of a wide range of specimens, the area method is generally more favorable. Here, strain energy release rate is calculated from the load - displacement ( $P$ vs. $\delta$ ) curve obtained during a test. For an infinitesimal increase in debond length, $d a$, the energy release rate is given by:

$$
G=\frac{1}{b} \frac{d U}{d a}
$$

where $U$ is the total elastic strain energy in the specimen (area beneath the $P$ vs. $\delta$ curve, see Figure 1b), $b$ is the specimen width and $d a$ is the increase in debond length recorded during the test. The test can be repeated for several load/un-load cycles and the energy released for an incremental $d a$ can be estimated using Equation (1).

Due to the inherent high elastic mismatch present across a sandwich interface, the crack propagation occurs in mixed mode condition. The mode mixity can be described as the measure of shear loading at the crack tip. Therefore, the energy release rate at a bi-material fracture interface is a function of mode mixity as described in [12]. In order for the SCB test to be useful as a "peel" or mode I dominant test, it must be ensured that the debond grows under mode I conditions corresponding to a peel dominated loading on the face sheet. The mode mixity at the crack tip is expressed in terms of a phase angle, $\psi$, which is the arc tangent of the ratio of sliding to opening displacement of the crack tip [12]. The reader must note that mode mixity and phase angle can be used interchangeably. The principle of Linear Elastic Fracture Mechanics (LEFM) applied to brittle materials can also be extended to study face/core interface. The failure process zone in terms of crack tip plasticity is very small in brittle materials. This is also valid for sandwich structures, with the exception of specimens with tougher cores or which exhibit fibre bridging resulting in a larger failure process zone.

Efforts are underway to develop an ASTM International testing standard to determine the peel-dominated fracture toughness of sandwich constructions using the SCB sandwich specimen. The SCB fracture test, when developed as an industrial standard, is poised to be used by different industry clientele and in configurations in which the stiffness mismatch across the sandwich interface varies with each user. To establish a reliable test protocol, the specimen must be designed such that a mode I condition prevails at all crack lengths. This implies that the SCB test must be robust enough to account for a wide variety of face/core combinations. The existing sizing study detailed in [13] was based on the beam on elastic 
foundation model approach [14]. Several limitations were imposed to ensure that the SCB sandwich specimen response remains linear during testing and the shear component at the crack tip was minimized. In addition, by restricting the specimen geometry, pre-crack length (a), loading rod length $\left(L_{\text {rod }}\right)$, maximum crack length $\left(\mathrm{a}_{\max }\right)$ and face sheet and core thicknesses $\left(h_{f}, h_{c}\right)$, to certain values, the specimen yields a linear response. However, in reality not all specimens used across industries yield linear responses, e.g. specimens with thin face sheets $\left(h_{f} \leq 0.5 \mathrm{~mm}\right)$ exhibit a non-linear unloading curve.

The compliance based solution outlined in [13] does not ensure that the pre-crack advances along the interface. The measured energy release rate during the test must be associated with interface crack propagation as the fracture toughness of a core material is much lower. Since the crack advances through an interface between dissimilar materials, the mode mixity condition determines whether the crack will enter the core, propagate along the interface or kink into the face sheet. Thus, limiting the SCB specimen dimensions solely based on kinematic analyses overlooks the local mode mixity condition at the crack tip.

An extensive experimental campaign to determine the mode mixity influence in the SCB test, by taking into account a wide variety of core and face sheet material systems, would be expensive. Moreover, a closed-form expression to ascertain the mode mixity at various crack lengths for the SCB sandwich specimen has not appeared in the literature. Hence, the objective of the current work was to conduct a parametric analysis studying the influence of various material and geometrical parameters of the SCB sandwich specimen on the mode mixity. The analysis was based on a numerical fracture mechanical tool, the Crack Surface Displacement Extrapolation (CSDE) method [15]. It must be noted that the thermal residual stresses affecting the crack tip loading conditions were not considered. A crack in a sandwich face/core interface propagates just beneath the interface, and was modelled as an interface crack between two dissimilar materials. The bi-material problem was treated in plane strain, and LEFM was considered to be valid.

Hypothetical sandwich material systems were studied initially to identify the influence of critical governing parameters that influence the crack tip mode mixity. The phase angle, $\psi$, evaluated for various face/core interfaces aids in identifying whether the fracture test remains in a mode I regime at all crack lengths. In terms of the phase angle (in degrees), pure mode I corresponds to $0^{\circ}$, and $90^{\circ}$ corresponds to a pure mode II loading at the crack tip. Therefore, in this analysis mode I dominance was considered within the bounds: $-10^{\circ} \leq \psi \leq 10^{\circ}$. A case study is presented by taking into account representative sandwich composite systems used in three different industries. Sizing parameters derived in [13] were closely examined and their influence on the phase angle, $\psi$, was studied. A discussion on the mode mixity phase angle and implementation of the CSDE method are provided in the following section. 


\section{Finite element modeling of the SCB sandwich specimen}

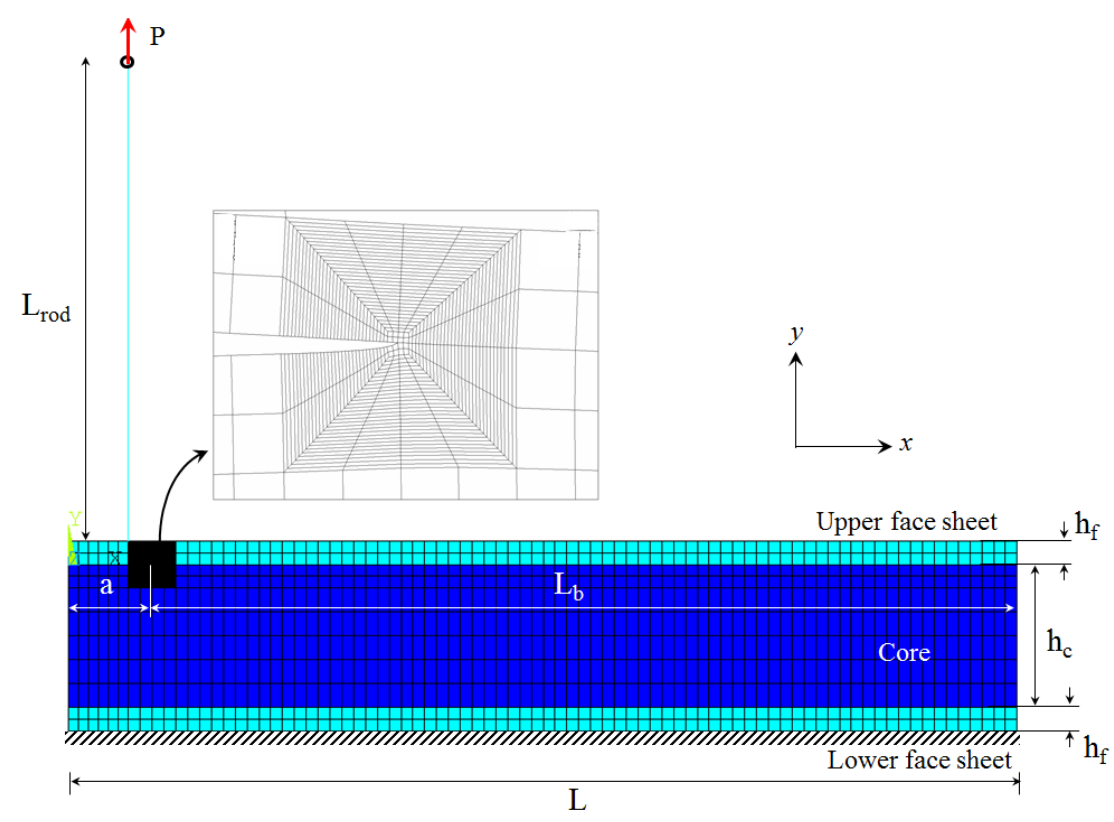

Figure 2. 2-D finite element model of SCB sandwich specimen with highly discretized mesh at the crack tip.

A 2-D plane-strain finite element (FE) model consisting of isoparametric 4-node linear (PLANE182) and 8-node parabolic (PLANE183) elements was built in ANSYS ${ }^{\circledR}$ [16], with the smallest element edge length of $2.5 \mu \mathrm{m}$ (see Figure 2). PLANE182 elements with 4 corner nodes supporting two degrees of freedom were used at the crack tip to capture large strains. The rest of the model was built using 8-node PLANE183 elements containing two translation degrees of freedom on each node. Highly densified meshing was employed at the crack tip zone for the CSDE mixed-mode partitioning method implementation. The loading rod was modeled using a beam element, hinged above the top face sheet, which takes only tension. The hinge leaf was not considered in the analysis. Unit load per width $(P / b=$ $1 \mathrm{~N} / \mathrm{mm}$ ) was applied on top of the rod. The base was modeled by applying fixed boundary conditions on the lower face sheet. The crack flanks in the debonded region were modeled as frictionless contact surfaces to circumvent interpenetration or overlapping of the surfaces.

Both energy-release rate, $G$, and mode mixity phase angle, $\psi$, should be consistent in the crack tip displacement dominated field. A highly dense mesh was required close to the crack tip to accurately model this displacement field. Moreover, the zone was limited by two borders: an inner border in which numerical errors close to the crack tip corrupt the results because the elements close to the crack tip cannot calculate the correct displacement field, and an outer border where the external displacement starts to dominate (see Figure 3). The zone of numerical noise pertains to the small region close to the crack tip where the linear elastic solution shows that the stresses oscillate confined to that small zone. From several numerical investigations, it was observed that the transition from the external displacement 
field to the internal crack dominated field was linear with respect to nodal pairs, until the border to numerical error zone was reached [17]. Hence, both $G$ and $\psi$ in the linear transition zone (or $K$-dominant zone) can be linearly extrapolated to the crack tip. The CSDE method uses only the results from relative crack-flank displacements ( $\delta y$ and $\delta x$ ) to calculate both $G$ and $\psi$.

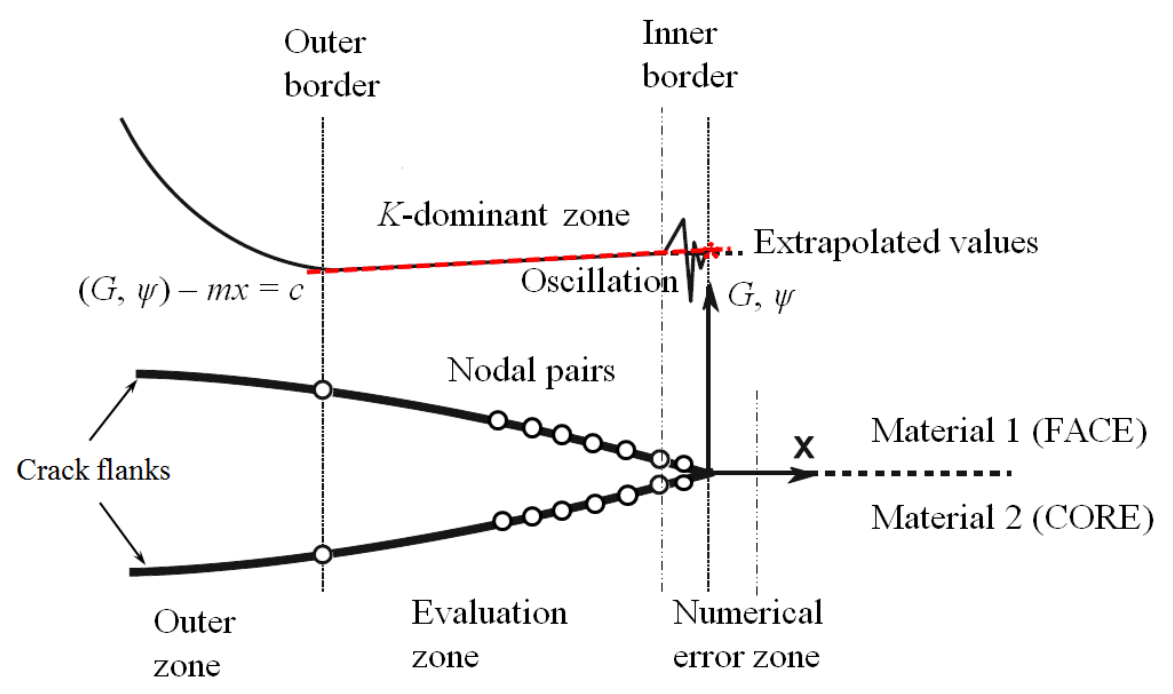

Figure 3. Schematic illustration of CSDE method implementation: face/core interface crack with sliding, $\delta x$ and opening, $\delta y$ displacements. $G$ and $\psi$ values are extrapolated from the $K$-dominant zone.

The phase angle, $\psi$, defines the ratio between mode II and mode I stress intensity factors of a bi-material interface crack. In terms of relative opening $\delta_{y}$ and sliding $\delta_{x}$ displacements (see Figure 3), the phase angle can be expressed as [12]:

$$
\psi_{F}=\tan ^{-1}\left(\frac{\delta_{x}}{\delta_{y}}\right)-\varepsilon \ln \left(\frac{x}{h}\right)+\tan ^{-1}(2 \varepsilon)
$$

where $x$ is a short distance within the singular region behind the crack tip, and $h$ is a characteristic length, usually chosen equal to the face sheet thickness, $h=h_{f}$. It was evident from the linear elastic solution that stresses and displacements oscillate near the crack tip [12]. The oscillatory index $\varepsilon$ is given by [12]:

$$
\varepsilon=\frac{1}{2 \pi} \ln \left(\frac{1-\beta}{1+\beta}\right)
$$

where $\beta$ is a non-dimensional bimaterial interface constant (Dundur's parameter) given by [18]:

$$
\beta=\frac{1}{2} \frac{S_{1}\left(1-2 v_{2}\right)-S_{2}\left(1-2 v_{1}\right)}{S_{1}\left(1-v_{2}\right)+S_{2}\left(1-v_{1}\right)}
$$


where $S_{1}$ and $S_{2}$ represent the shear moduli of face sheet and core located above and below the interface, respectively. The phase angle from Equation (2), calculated using the FE-based CSDE method with values of $\varepsilon$ and $\beta$ from Equations (3) and (4) and with $x=h_{f}$, is $\psi_{F}$, referred to as the "full formulation". Both $G$ and $\psi$ are affected by oscillations according to the linear elastic solution since stresses oscillate when the crack tip is approached. The influence of crack tip oscillation can be suppressed by assuming $\varepsilon$ $=0$ in Equation (2), which helps recover the conventional square-root based singular stress intensity factors [19]. Therefore, the phase angle in Equation (2) can be re-expressed in "reduced formulation" ( $\varepsilon$ $=0)$, as:

$$
\psi_{R}=\tan ^{-1}\left(\frac{\delta_{x}}{\delta_{y}}\right)
$$

Throughout this paper, the reduced formulation is used, and the phase angle will be denoted as $\psi$, without the subscript. The energy release rate obtained in terms of crack-flank displacements is given by [15]:

$$
G=\frac{\pi\left(\delta_{x}^{2}+\delta_{y}^{2}\right)}{2 x\left(\mathrm{c}_{1}+\mathrm{c}_{2}\right)}
$$

where $x$ is the distance from the crack tip and $c_{1}$ and $c_{2}$ are stiffness parameters of the face sheet and core given by:

$$
c_{m}=\frac{k_{m}+1}{S_{m}}
$$

The parameter $k_{m}=\left(3-4 v_{m}\right)$ for plane strain and $k_{m}=\left(3-v_{m}\right) /\left(1+v_{m}\right)$ for plane stress, where $v_{m}$ is Poisson's ratio with $m=1$ and 2 for the face sheet and core, respectively.

A separate subroutine was implemented in the program ANSYS ${ }^{2}[16]$ where sliding $(\delta x)$ and opening $(\delta y)$ crack-flank displacements were extracted. The CSDE method is very effective in calculating both $G$ and $\psi$ when distortions in the near tip elements are present, especially in the case of sandwich where an elastic mismatch across the face/core interface exists. It should be noted that the CSDE method can analyze phase angles in both reduced and full formulation (Equations 2 and 5). If $\psi>0$, the crack is directed towards the core, whereas if $\psi<0$, the crack is directed toward the face sheet. A mode I dominant window was assumed to exist in the phase angle regime: $-10^{\circ} \leq \psi \leq 10^{\circ}$. 


\section{SCB parametric fracture analysis}

The SCB specimen is intended for mode I fracture testing of a wide array of face/core material systems. Typical through-thickness core moduli varies from $76 \mathrm{MPa}$ (Nomex Honeycomb used in Aerospace industry) to $6840 \mathrm{MPa}$ (high density balsa widely employed in the marine and wind energy sectors). Face sheet and core thicknesses of sandwich systems invariably differ based on the application. Correct loading rod length in the SCB test was paramount in preventing shear loading at the load application point. Testing frame heights and cross head displacement capacities vary at different test labs. Therefore, it is necessary to stipulate the loading rod length $\left(L_{r o d}\right)$ to enable robustness of the SCB fracture test methodology.

A parametric study of the SCB sandwich specimen was conducted using the finite-element model presented in the previous section in conjunction with the CSDE method. A unit load $P=1 \mathrm{~N} / \mathrm{mm}$ was applied on a pre-cracked specimen for all cases. The list of parameters considered to determine whether the fracture testing remains under mode I conditions is provided in Table 1. For the initial study, Poisson's ratio of both face sheet and core were held constant at $v_{f}=0.30$ and $v_{c}=0.35$. A separate section is dedicated to investigating the effect of core Poisson's ratio, $v_{c}$. The length of the hinge was kept constant throughout the analysis, $L_{\text {hinge }}=12.7 \mathrm{~mm}$ and the total length of the specimen is given by: $L=L_{\text {hinge }}+\mathrm{a}_{\max }+L_{b}$. The compliance based solution in [13] and [20] recommended a minimum intact length of the specimen $\left(L_{b}\right)$, by stipulating that the compliance coefficients remain at unity; $L_{b}$ is given by:

$$
L_{b, \min }=2.7\left[\frac{h_{c} h_{f}^{3} E_{f}}{3 E_{c}}\right]^{1 / 4}
$$

The maximum debond length was fixed to $\mathrm{a}_{\max }=150 \mathrm{~mm}$ for all cases in the analysis. By selecting a specimen length, $L=300 \mathrm{~mm}$, the intact length $\left(L_{b}\right)$ was found to satisfy the minimum recommended length in Equation (8) for all combinations of materials considered in Table 1. The effect of intact portion length on mode mixity is presented later. To study the effect of different combinations of the parameters (see Table 1) on the mode mixity phase angle $(\psi)$, the parameters are varied in steps in the numerical study. Using the values shown in Table 1, calculated values of $\alpha=\left(\bar{E}_{1}-\bar{E}_{2}\right) /\left(\bar{E}_{1}+\bar{E}_{2}\right)$ varied from 0.65 to 0.99 typical values found in a sandwich face/core interface. The Young's modulus for plane stress and plane strain conditions are given by, $\bar{E}=E$ and $\bar{E}=E /\left(1-v^{2}\right)$, respectively, with subscripts $1=$ face sheet and $2=$ core. 
Table 1. Parameters altered in the SCB parametric study.

SCB Parameters

Core modulus, $E_{c}[\mathrm{MPa}]$

Face sheet Modulus, $E_{f}[\mathrm{GPa}]$

Core thickness, $h_{c}[\mathrm{~mm}]$

Face sheet thickness, $h_{f}[\mathrm{~mm}]$

Loading rod length, $L_{\text {rod }}[\mathrm{mm}]$
$100,500,1000$

$5,10,50,100,200,250$

10,40

$0.5,3,7$

$120,250,500$

Table 2. Possible $\Sigma=E_{f} / E_{c}$ values for $E_{c}=100,500$ and $1000 \mathrm{MPa}$.

\begin{tabular}{|c|c|c|c|}
\hline $\boldsymbol{E}_{\boldsymbol{f}}\left[\mathbf{M P a} \boldsymbol{\boldsymbol { E } _ { \boldsymbol { c } } [ \mathbf { M P a } ]}\right.$ & 100 & 500 & 1000 \\
\hline $5 \cdot 10^{3}$ & 50 & 10 & 5 \\
\hline $10 \cdot 10^{3}$ & 100 & 20 & 10 \\
\hline $50 \cdot 10^{3}$ & 500 & 100 & 50 \\
\hline $100 \cdot 10^{3}$ & 1000 & 200 & 100 \\
\hline $200 \cdot 10^{3}$ & 2000 & 400 & 200 \\
\hline $250 \cdot 10^{3}$ & 2500 & 500 & 250 \\
\hline
\end{tabular}

\section{Effect of core and face sheet modulus $\left(\Sigma=E_{f} / E_{c}\right)$}

The effect of both core and face sheet moduli on phase angle are presented in this section. Three core moduli were chosen $E_{c}=100,500$ and $1000 \mathrm{MPa}$, and face sheet moduli were chosen in the range, $E_{f}=$ 5 to $250 \mathrm{GPa}$ (see Table 1). The range of $\Sigma=E_{f} / E_{c}$ values are provided in Table 2. Three face sheet thicknesses were chosen: $h_{f}=0.5,3$ and $7 \mathrm{~mm}$, and core thickness was $h_{c}=40 \mathrm{~mm}$. The length of the loading rod was $L_{\text {rod }}=500 \mathrm{~mm}$, and length of the specimen was $L=300 \mathrm{~mm}$. To capture non-linear effects associated with specimens with thin face sheets, a geometrically non-linear Finite Element Analysis (FEA) was performed.

Figure 4 shows the variation of phase angle $(\psi)$ for a $40 \mathrm{~mm}$ thick core with three core moduli: $E_{c}=100$, 500 and $1000 \mathrm{MPa}$. Figures 4(a) - 4(c) show results for $E_{c}=100 \mathrm{MPa}$ at three face sheet thicknesses. Figures 4(d) $-4(\mathrm{f})$ and $4(\mathrm{~g})-4(\mathrm{i})$ show corresponding results for $E_{c}=500 \mathrm{MPa}$ and $E_{c}=1000 \mathrm{MPa}$, respectively. In Figure 4, the region not satisfying the assumed mode I dominant bound $\left(-10^{\circ} \leq \psi \leq 10^{\circ}\right)$ was identified. 
For the case of a low modulus core $\left(E_{c}=100 \mathrm{MPa}\right)$ with a thin face sheet, the phase angle $(\psi)$ increased with $\Sigma$ for short crack lengths, a $\sim 30 \mathrm{~mm}$ (see Figure. 4a). A similar trend with a thin face sheet $\left(h_{f}=\right.$ $0.5 \mathrm{~mm}$ ) was observed for stiffer cores (see Figures. $4 \mathrm{~d}$ and $4 \mathrm{~g}$ ). For all core moduli considered here, $\psi$ increased with $\Sigma$. For the case of $E_{c}=100 \mathrm{MPa}$, mode I dominant behavior was observed at small values of $\Sigma(\Sigma \leq 500)$.

It was noted with increased core stiffness and small values of $\Sigma$, the phase angle $(\psi)$ shifts toward the negative region. It was also noted that $\psi$ was largely positive $\left(>10^{\circ}\right)$ for all cases except when $\Sigma<100$. For the case of a stiff core $\left(E_{c}=1000 \mathrm{MPa}\right)$, negative values of $\psi\left(<0^{\circ}\right)$ were observed for small values of $\Sigma$ (see Figures $4 \mathrm{~g}$-i). Therefore, there was a strong influence on the mode mixity by both face sheet stiffness and core modulus. 


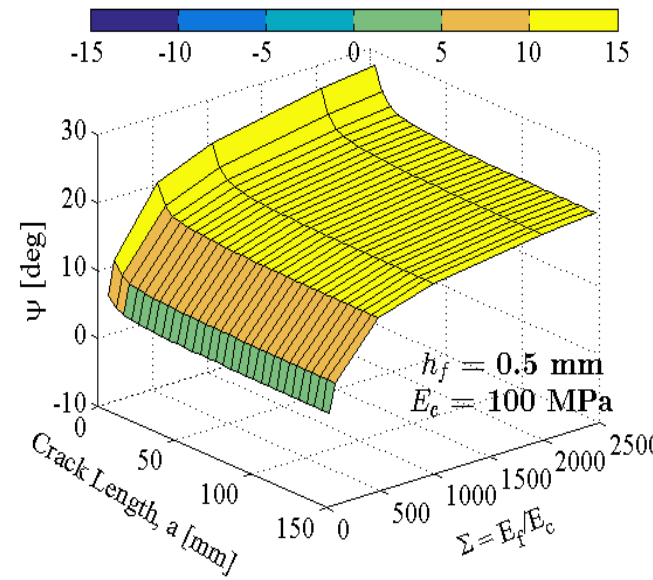

(a)
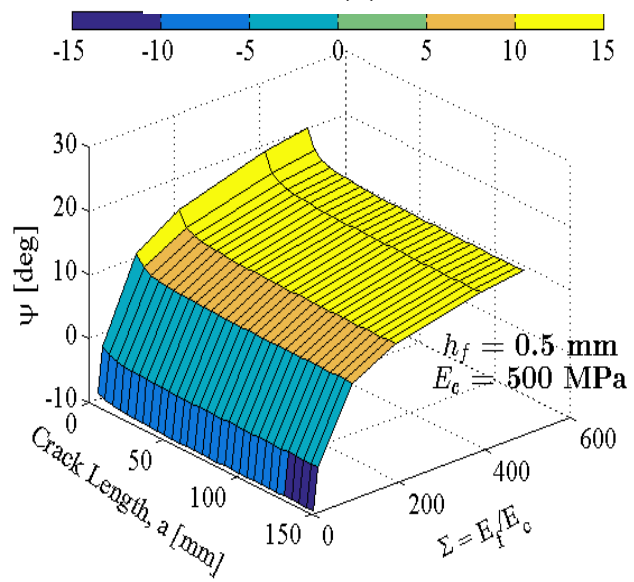

(d)

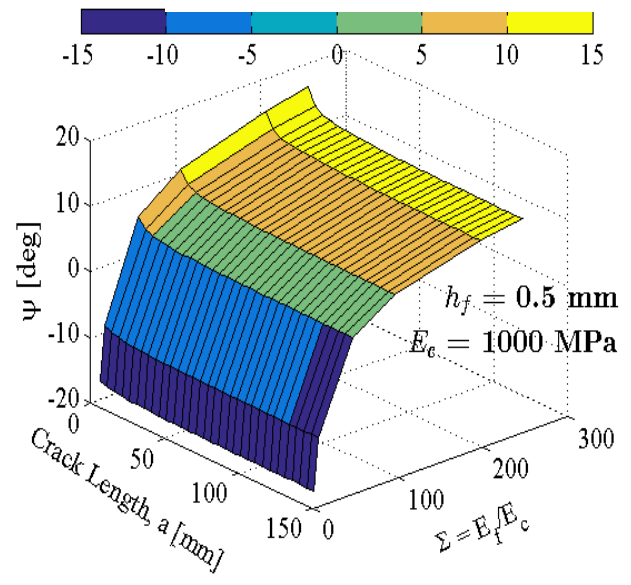

(g)

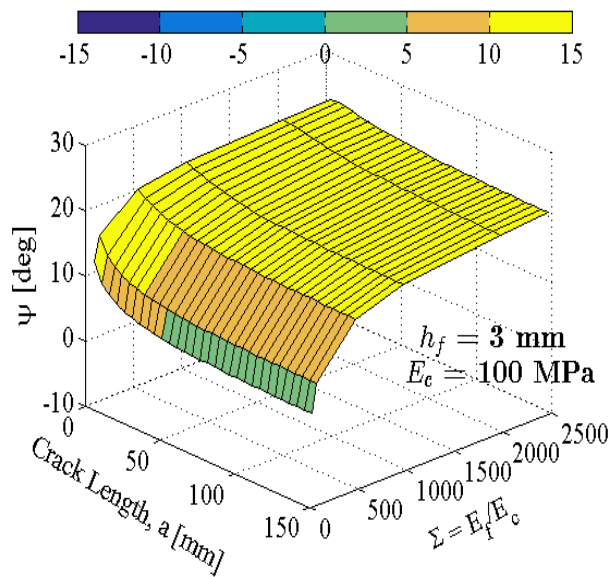

(b)

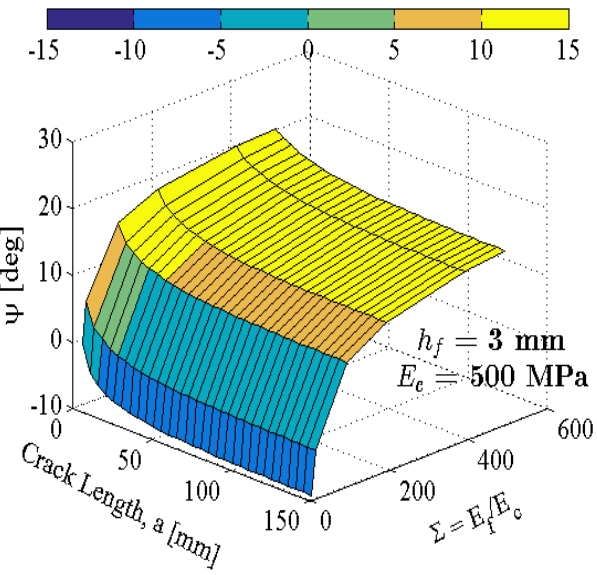

(e)

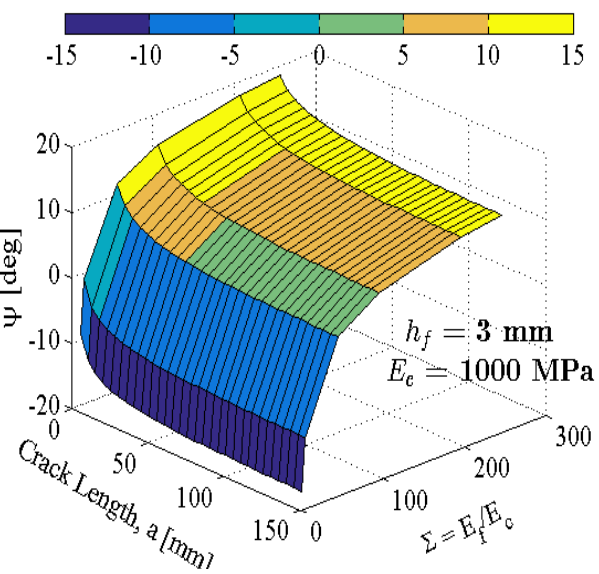

(h)

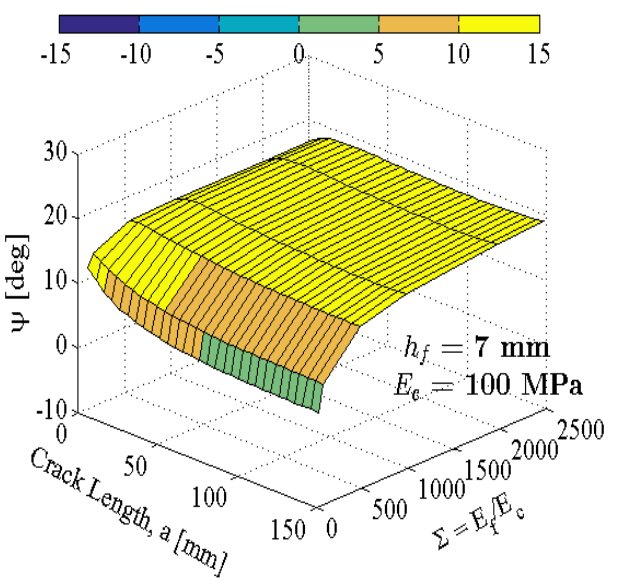

(c)

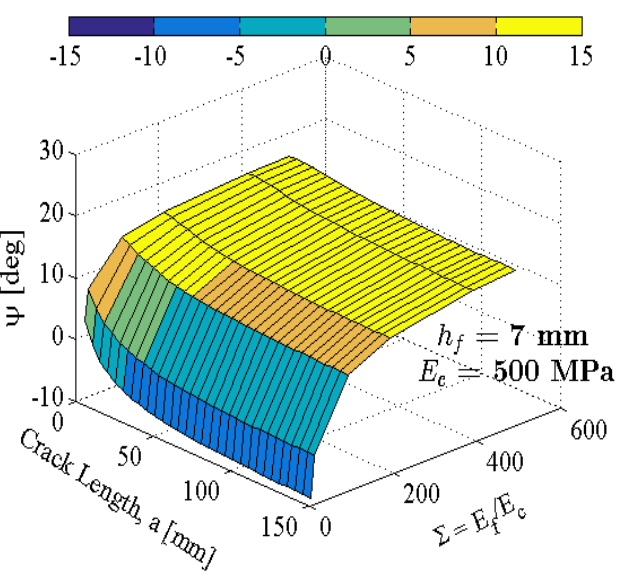

(f)

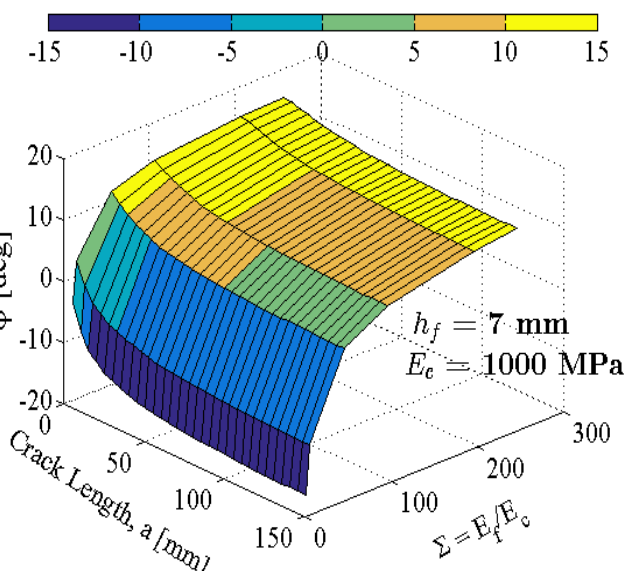

(i)

Figure 4. Mode mixity phase angle ( $\psi$ ) vs. crack length with $L_{r o d}=500 \mathrm{~mm}, h_{c}=40 \mathrm{~mm}, L=300 \mathrm{~mm}$ for $E_{c}=100 \mathrm{MPa}:$ (a) $h_{f}=0.5 \mathrm{~mm}$, (b) $h_{f}=3 \mathrm{~mm}$ (c) $h_{f}=7 \mathrm{~mm}, E_{c}=500 \mathrm{MPa}$ : (d) $h_{f}=0.5 \mathrm{~mm}$ (e) $h_{f}$ $=3 \mathrm{~mm}$ (f) $h_{f}=7 \mathrm{~mm}$ and $E_{c}=1000 \mathrm{MPa}:(\mathrm{g}) h_{f}=0.5 \mathrm{~mm}$ (h) $h_{f}=3 \mathrm{~mm}$ (i) $h_{f}=7 \mathrm{~mm}$. 


\section{Effect of core Poisson's ratio (vc)}

The crack tip mode mixity condition was influenced by crack tip root rotation [21]. In sandwich systems, the core is less stiff compared to the face sheets, contributing to the deformation and rotation of the upper face sheet. The effect of core Poisson's ratio $\left(v_{c}\right)$ on mode mixity phase angle $(\psi)$ was investigated using the SCB FE-model. For the analysis, the core modulus was held constant at $E_{c}=100 \mathrm{MPa}$, and the face sheet modulus was chosen in the range $E_{f}=5$ to $250 \mathrm{GPa}$ (see Table 2). Rod length, face sheet thickness, core thickness and length of the SCB specimen were held constant at: $L_{r o d}=500 \mathrm{~mm}, h_{f}=2 \mathrm{~mm}, h_{c}=40$ $\mathrm{mm}$ and $L=300 \mathrm{~mm}$. The core Poisson's ratio was varied from $v_{c}=0.15$ to 0.45 , and the phase angle was computed for each case. Figure 5(a) shows a plot of $\psi$ vs. crack length for three $v_{c}$ values for $50 \leq \Sigma$ $\leq 2500$. As shown in the plot, $\psi$ was strongly dependent on the core Poisson's ratio.

The phase angle, $\psi$, remains higher for a core with lower Poisson's ratio, $v_{c}$, over the entire range of $\Sigma=$ $E_{f} / E_{c}$ values. For better inspection, a slice from Figure 5(a) is presented in Figure 5(b) for $\Sigma=100$. It can be noted that for the case, $v_{c}=0.45, \psi$ remains in the mode I regime $\left(-10^{\circ} \leq \psi \leq 10^{\circ}\right)$ for all crack lengths. As $v_{c}$ decreased, $\psi$ increased causing the mode mixity to deviate away from mode I condition. At the maximum crack length considered here $(\mathrm{a}=150 \mathrm{~mm})$, the mode mixity varies from $\psi=25^{\circ}$ for $v_{c}=0.15$ to $\psi=-5^{\circ}$ for $v_{c}=0.45$ (see Figure $5 \mathrm{~b}$ ). However, for a constant core Poisson's ratio $\left(v_{c}\right)$, the change in $\psi$ across crack lengths remains negligible for a $>20 \mathrm{~mm}$. Therefore, both stiffness and Poisson's ratio of the core influence $\psi$ and cause the test to deviate away from mode I conditions.

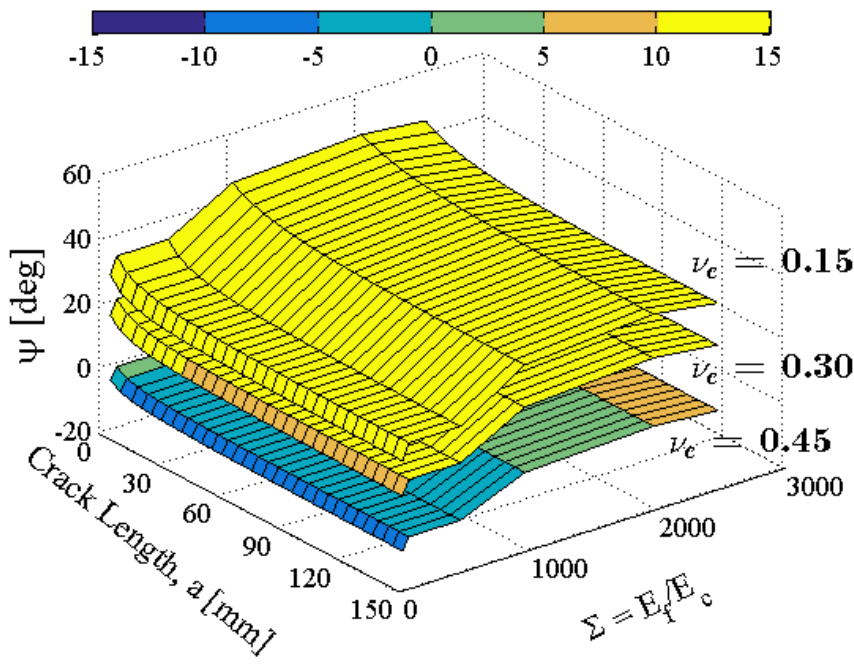

(a)

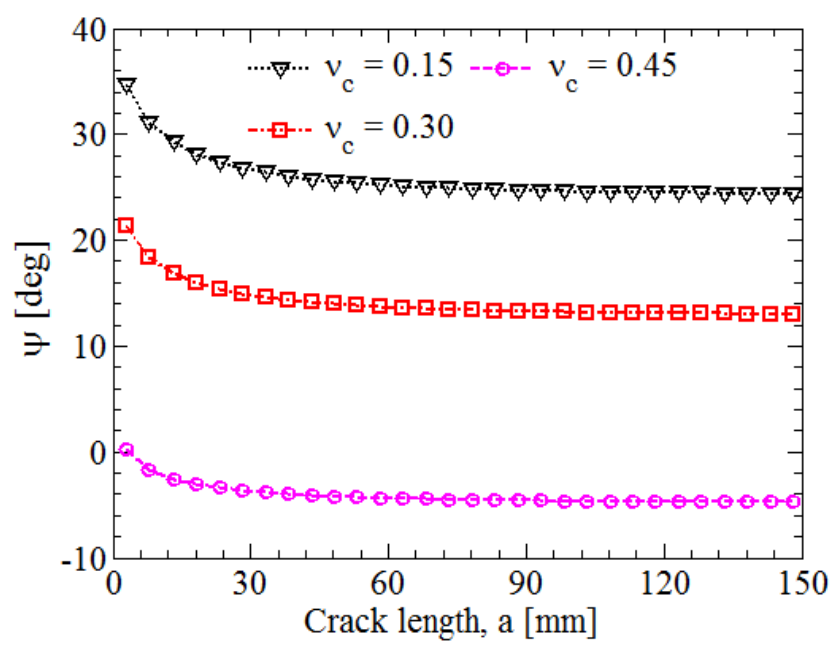

(b)

Figure 5. Mode mixity phase angle ( $\psi$ ) vs. crack length (a) for various $\Sigma$ values (b) $\psi v s$. crack length at $\Sigma=100$. $\left(h_{c}=40 \mathrm{~mm}, h_{f}=2 \mathrm{~mm}, L=300 \mathrm{~mm}, L_{r o d}=500 \mathrm{~mm}, v_{c}=0.15,0.30\right.$ and 0.45$)$. 


\section{Effect of face sheet and core thickness $\left(h_{f}, h_{c}\right)$}

To investigate the influence of face sheet and core thicknesses on the phase angle $(\psi)$, the face sheet thickness $\left(h_{f}\right)$ was varied from $0.5 \mathrm{~mm}$ to $7 \mathrm{~mm}$ for two different core thicknesses $\left(h_{c}=10 \mathrm{~mm}\right.$ and 40 $\mathrm{mm})$. The face sheet and core moduli were considered as: $E_{f}=5 \cdot 10^{3} \mathrm{MPa}$ and $E_{c}=100 \mathrm{MPa}(\Sigma=50)$. Loading rod length was kept constant at $L_{r o d}=500 \mathrm{~mm}$, and total length of the specimen, $L=300 \mathrm{~mm}$. A plot of $\psi$ vs. crack length is shown in Figure 6 for the two core thicknesses, $h_{c}=10$ and $40 \mathrm{~mm}$.

For the thin core case $\left(h_{c}=10 \mathrm{~mm}\right), \psi$ leveled to a plateau for a $>40 \mathrm{~mm}$ for all cases of face sheet thicknesses considered. It was noted that a thicker face sheet had the tendency to drive the crack into the negative mode mixity regime (see Figure $6(\mathrm{a})$ ). For the thick core $\left(h_{c}=40 \mathrm{~mm}\right)$ considered here, mode mixity becomes increasingly positive with increased face sheet thickness (Figure $6 b$ ).

The difference in $\psi$ between thin $(0.5 \mathrm{~mm})$ and thick $(7 \mathrm{~mm})$ face sheets for the case of a thick core was small at larger crack lengths $\left(\sim 2^{\circ}\right)$. Furthermore, in the case of thick core $\left(h_{c}=40 \mathrm{~mm}\right)$, for face sheet thickness $h_{f} \geq 1.5 \mathrm{~mm}$ at short crack lengths, the mode mixity deviated away from the mode I regime. Thus, the energy release rate computed at short crack lengths laid outside the mode I regime. When the phase angle was positive $\left(\psi>0^{\circ}\right)$, the inclination of crack was to enter the core. For $\psi<0^{\circ}$, and with tough face sheets, the crack propagates along the interface verses kinking into the core.

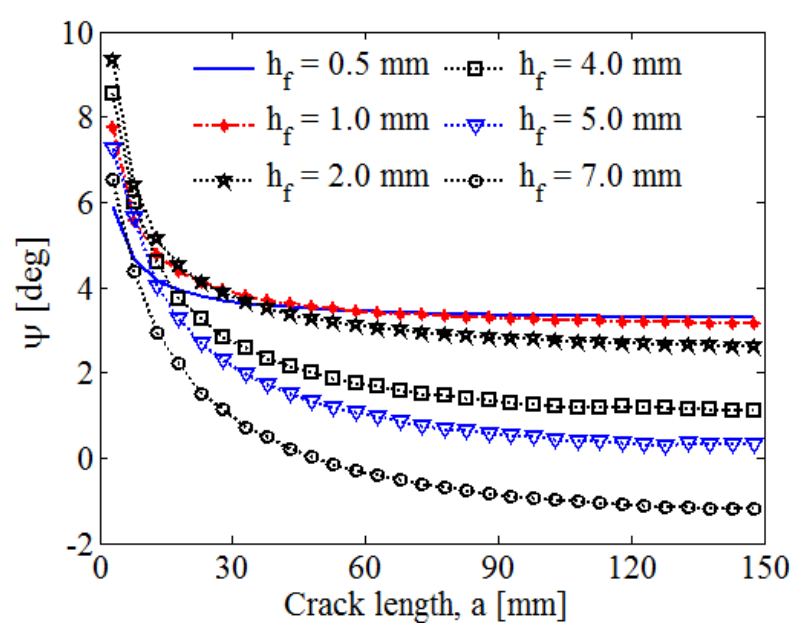

(a)

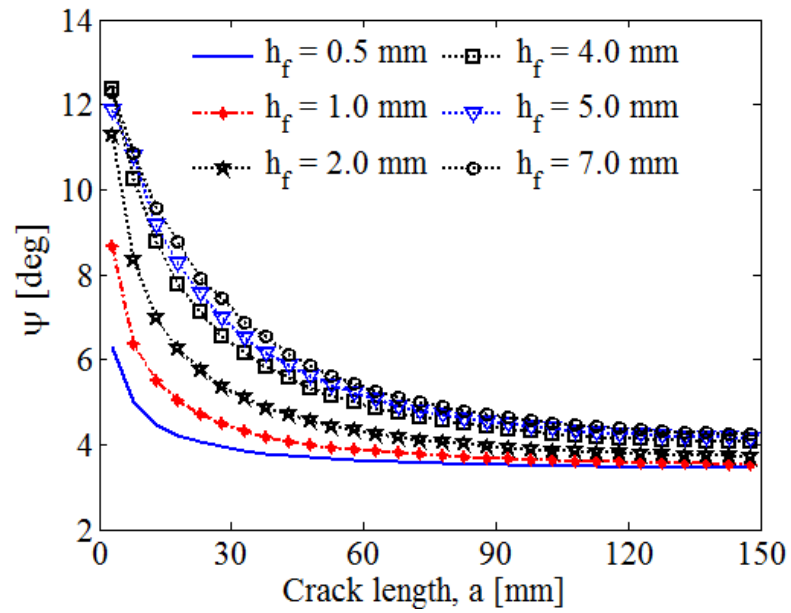

(b)

Figure 6. Phase angle $(\psi)$ vs. crack length for $\Sigma=50\left(E_{f}=5 \mathrm{GPa}, E_{c}=100 \mathrm{MPa}\right)$ for core thickness; (a) $h_{c}=10 \mathrm{~mm}$ (b) $h_{c}=40 \mathrm{~mm}$. ( $L_{\text {rod }}=500 \mathrm{~mm}$ and $L=300 \mathrm{~mm}$ for both cases $)$. 


\section{Effect of intact length $\left(L_{b}\right)$ and elastic foundation modulus $(k)$}

The influence of SCB specimen intact length $\left(L_{b}\right)$ and elastic foundation modulus on the phase angle $(\psi)$ are discussed in this section. The top face sheet was perceived as a beam resting on a linear elastic foundation [14]. Li et al. [20] derived the deformation of a top face sheet for a Tilted Sandwich Debond (TSD) [22] specimen by using the Winkler foundation model first utilized by Kanninen [14]. The beam on foundation approach of the TSD specimen was extended to the SCB specimen in [13].

The SCB specimen was sized in order to ensure that the global shear deformation introduced on the debonded upper face sheet remains negligible. The intact part of the SCB specimen $\left(L_{b}\right)$ plays a key role in reducing the shear component and must be kept above a minimum length such that $\lambda L_{b} \geq 2.7$ [13], where parameter $\lambda$ is the ratio of stiffness of the elastic foundation to the bending stiffness of the upper face sheet:

$$
\lambda=\left[\frac{3 k}{E_{f} h_{f}^{3} b}\right]^{1 / 4}
$$

where $b$ is the width of SCB specimen. Several expressions for $k$ exist in the literature, of which three are shown in Table 3. The minimum required intact length $\left(L_{b, \min }\right)$ for a SCB specimen was given by [13]:

$$
L_{b, \min }=\frac{2.7}{\lambda}
$$

Table 3 shows $\lambda$ and the minimum required length stipulated by Equation (10) computed for a hypothetical sandwich configuration comprised of an aluminum face sheet $\left(E_{f}=68.9 \mathrm{GPa}, h_{f}=7 \mathrm{~mm}\right)$ and a PVC DIAB H100 $\left(E_{c}=130 \mathrm{MPa}, h_{c}=25.4 \mathrm{~mm}\right)$ core [23].

Table 3. Minimum intact length $\left(L_{b, m i n}\right)$ calculated using elastic foundation modulus $(k)$ expressions for $E_{f}=68.9 \mathrm{GPa}, h_{f}=7 \mathrm{~mm}$ and $E_{c}=130 \mathrm{MPa}, h_{c}=25.4 \mathrm{~mm}$.

\begin{tabular}{|l|c|c|c|}
\hline Elastic Foundation Modulus & $\boldsymbol{k}$ [MPa] & $\left.\boldsymbol{\lambda} \mathbf{~ m m}^{-1}\right]$ & $\boldsymbol{L}_{b, \boldsymbol{m i n}}$ [mm] \\
\hline Li et al. [20]; $k=\frac{E_{c} b}{h_{c}}$ & 5.31 & 0.028 & 94.21 \\
\hline Aviles et al. [24]; $k=\frac{2 E_{c} b}{h_{c}}$ & 10.63 & 0.034 & 79.22 \\
\hline Quispitupa et al. [25]; $k=\frac{2 E_{c} b}{h_{f}}$ & 38.57 & 0.047 & 57.40 \\
\hline
\end{tabular}


The recommended minimum length $\left(L_{b, \min }\right)$ ensured that the shear component remains negligible. Therefore, if a fracture test was conducted with a specimen which does not satisfy Equation (10), the mode mixity phase angle $(\psi)$ deviated from the mode I regime. A numerical study was carried out to check if any variation in $\psi$ occurs when insufficient intact length was used. Two specimen lengths, $L=$ 200 and $300 \mathrm{~mm}$, with a maximum crack length, $\mathrm{a}_{\max }=150 \mathrm{~mm}$, were considered. This means that when $\mathrm{a}_{\max }=150 \mathrm{~mm}$, the intact portion length was $50 \mathrm{~mm}$ for the former and $150 \mathrm{~mm}$ for the latter case. The analysis was performed for face sheet thicknesses in the range: $h_{f}=0.5$ to $7 \mathrm{~mm}$. A plot of $\psi$ vs. crack length is provided in Figure 7 for both specimen lengths $(L=200$ and $300 \mathrm{~mm})$.

For a face sheet thickness $h_{f}=7 \mathrm{~mm}$, Table 3 showed that the foundation modulus expression $(k)$ by Li et al. [20] yields a maximum value $L_{b, \min }=94.21 \mathrm{~mm}$, whereas the lowest value $L_{b, \min }=57.40 \mathrm{~mm}$, was obtained using the modulus by Quispitupa et al. [25]. The intact length in Figure 7(a) is $L_{b}=L-\mathrm{a}_{\max }=$ $50 \mathrm{~mm}$, less than the recommended lengths $\left(L_{b, \min }\right)$ listed in Table 3 . The phase angle $(\psi)$ for $h_{f}=0.5 \mathrm{~mm}$ remained nearly constant for a $>30 \mathrm{~mm}$, and for $h_{f}=2 \mathrm{~mm}$ a slight deviation in $\psi$ was observed at a $=$ $130 \mathrm{~mm}$. Significant influence on $\psi$ is observed for $h_{f} \geq 4 \mathrm{~mm}$. For $h_{f}=4 \mathrm{~mm}$, the phase angle $(\psi)$ started to spike at a $=120 \mathrm{~mm}$, and for the thicker $h_{f}=7 \mathrm{~mm}, \psi$ spiked at a $=90 \mathrm{~mm}$. In Figure 7(b), no deviation in $\psi$ from the plateau occurred for all face sheet thicknesses attributed to a longer specimen length. Therefore, in line with the observations made here, careful selection of the SCB specimen length and maximum crack length were required to ensure that fracture testing is conducted in the mode I region over all ranges of crack lengths. The intact portion length obtained using Li et al. [20] captures the shift in mode mixity very well compared to other elastic foundation modulus expressions, and recommended for use in estimation of $L_{b}$ for a given $\mathrm{a}_{\max }$.

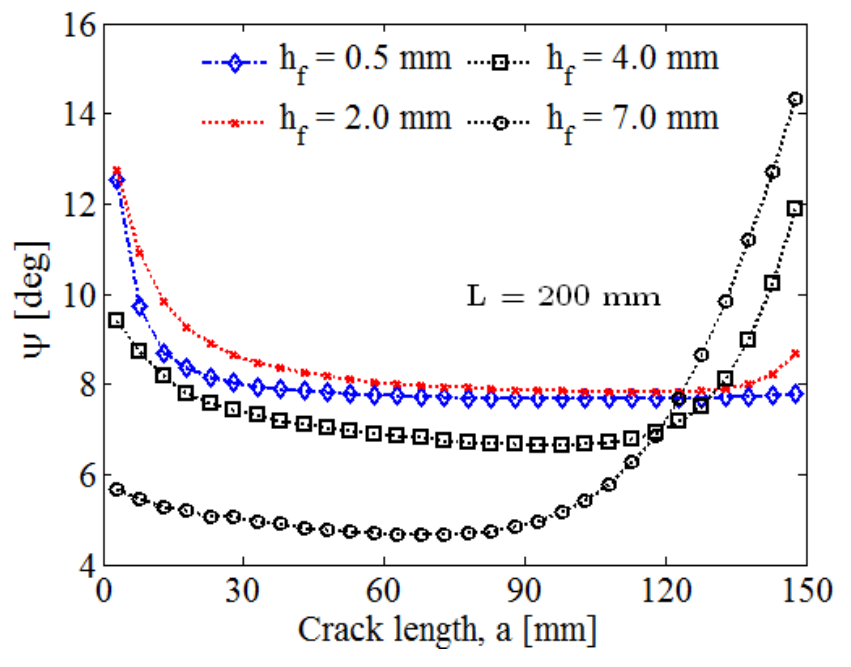

(a)

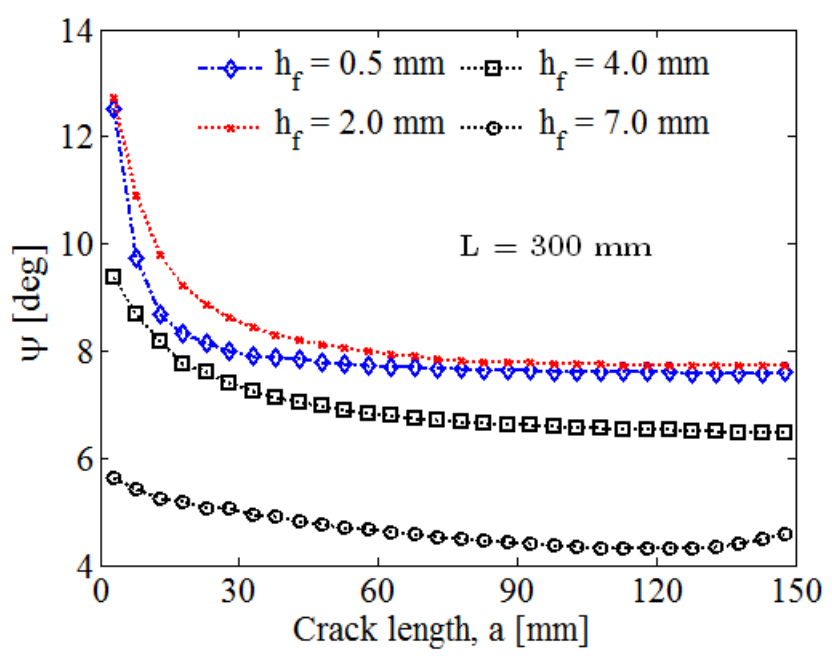

(b)

Figure 7. Mode mixity phase angle vs. crack length for an Aluminum/H100 sandwich system; (a) $L=$ $200 \mathrm{~mm}$ (b) $L=300 \mathrm{~mm}$ with $\mathrm{a}_{\max }=150 \mathrm{~mm}$. 


\section{Effect of loading rod length $\left(L_{\text {rod }}\right)$}

In the $\mathrm{SCB}$ fracture test, it is paramount that the load introduction point always remain vertical and avoids any horizontal component, which introduces shear. A conservative estimate of a minimum loading rod length $\left(L_{r o d, m i n}\right)$ following the kinematic approximation in [20], was provided in [13]:

$$
L_{\text {rod, } \min }=1.06 \mathrm{a}_{\max }
$$

To prevent shear loading at the face/core interface, a long loading rod length is desired requiring a tall load frame. Analysis using the parametric numerical model from a mode mixity perspective was undertaken to investigate the effect of reducing the loading rod length from the recommended value. The maximum crack length in this analysis was $\mathrm{a}_{\max }=150 \mathrm{~mm}$ with a total length of the specimen, $L=300$ $\mathrm{mm}$. According to Equation (11), the minimum required length of the rod should be $159 \mathrm{~mm}$. Three different loading rod length cases $\left(L_{\text {rod }}=50,120\right.$ and $\left.500 \mathrm{~mm}\right)$ were considered, with core thickness kept constant at $h_{c}=25.4 \mathrm{~mm}$. The bi-material tensile moduli $\Sigma=E_{f} / E_{c}$ were 100,1000 and 2500 for this analysis with a constant core modulus $E_{c}=100 \mathrm{MPa}$. Only three values of $\Sigma$ were considered, since only a trend in the influence of various rod lengths was desired. The results of the analysis for three face sheet thicknesses $\left(h_{f}=0.5,3\right.$ and $\left.7 \mathrm{~mm}\right)$ are presented in Figure 8.

It is evident that a short loading rod length introduced a shear component leading to higher mode mixity values (see Figures. 8a-c). The difference in $\psi$ for 50 and $120 \mathrm{~mm}$ rod lengths was small, except at very short crack lengths (maximum $5^{\circ}$ ) and was indistinguishable in the current plot for the cases considered here. Longer rod lengths of 750 and $1000 \mathrm{~mm}$ showed no significant influence on $\psi$ compared to a rod length of $500 \mathrm{~mm}$ and thus have been omitted in the plot.

The influence of rod length on $\psi$ for a thicker face sheet, $h_{f}=7 \mathrm{~mm}$ is shown in Figure 8(c). For $h_{f}=7$ $\mathrm{mm}$ at short crack lengths $(\mathrm{a}<10 \mathrm{~mm})$, there was very little difference in $\psi$ between short and long rod lengths. The mode mixity deviates away from mode I regime at short crack lengths, as observed in previous sections. However, for a thin face sheet, $h_{f}=0.5 \mathrm{~mm}$, increasing the rod length shifts $\psi$ in to the mode I regime (see Figure $8 \mathrm{a})$. The variation of phase angle at short $(\mathrm{a}=30 \mathrm{~mm})$ and long $(\mathrm{a}=120 \mathrm{~mm})$ crack lengths were provided for a thick face sheet $\left(h_{f}=7 \mathrm{~mm}\right)$ case in Figure $8 \mathrm{~d}$ and $8 \mathrm{e}$. As observed, the longer rod length yielded lower values of $\psi$ at all values of $\Sigma$. It should be noted that plots in Figures $8 \mathrm{~d}$ and $8 \mathrm{e}$ were smoothed using an interpolation function to obtain a best trend. A minimum length $\left(L_{r o d}\right)$ of $500 \mathrm{~mm}$ is desired to ensure that $\psi$ remains in the mode I regime for the generality of sandwich systems. Therefore, a new rod length based on the specimen length was proposed, $L_{r o d} \geq 1.70 \mathrm{~L}$ to accommodate the generality of sandwich constructions. 


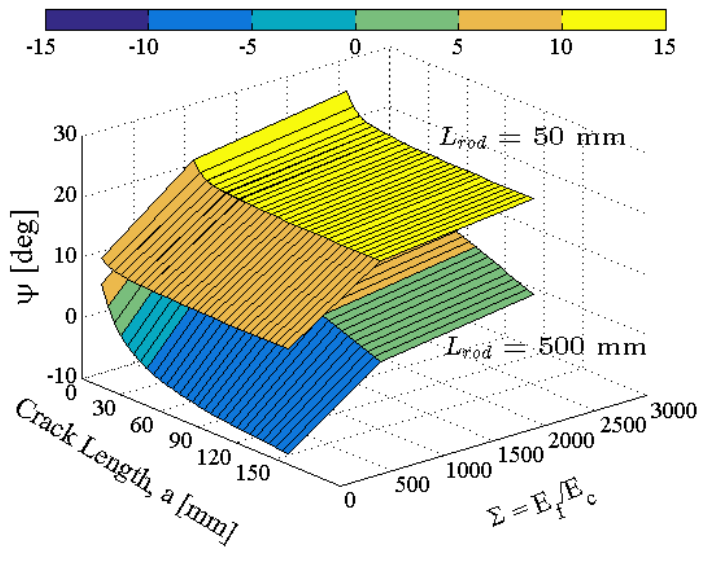

(a)

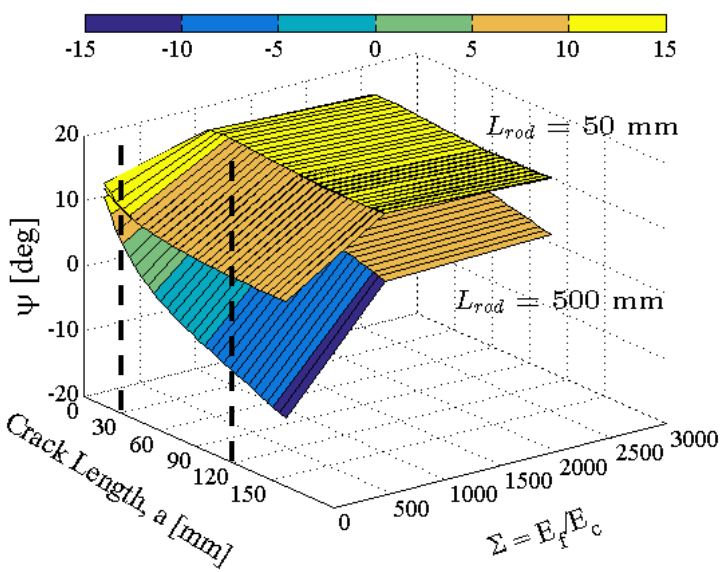

(c)

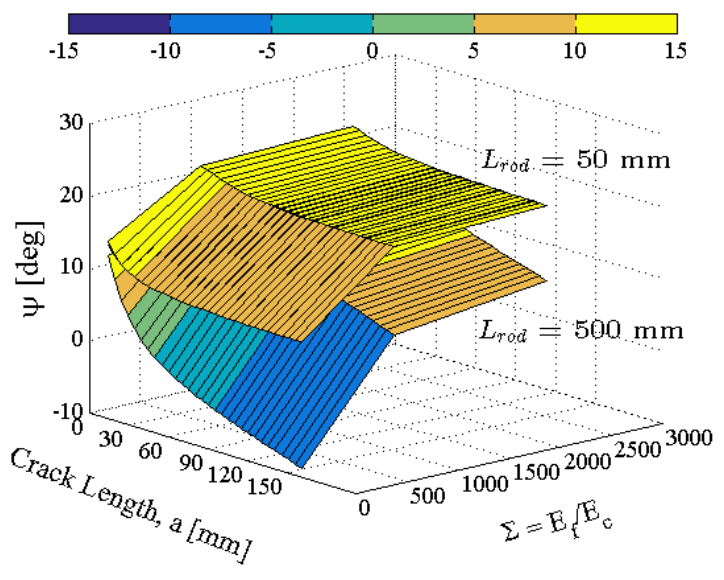

(b)

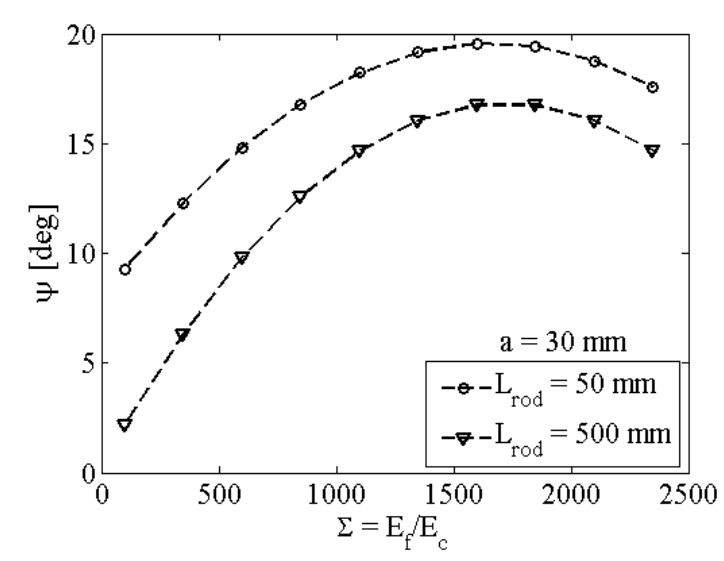

(d)

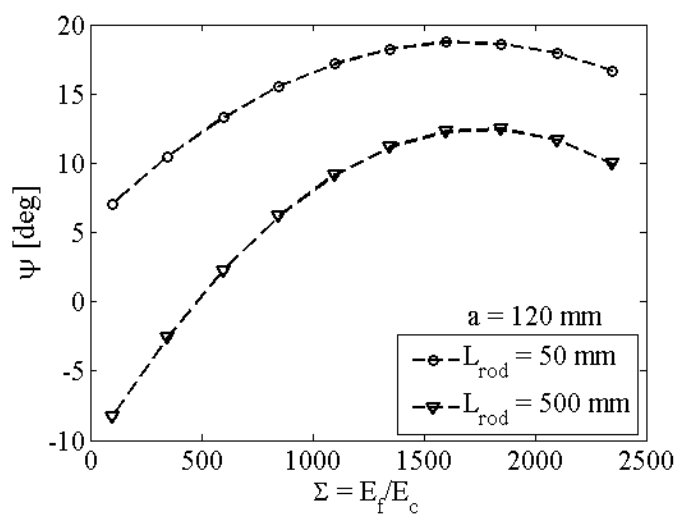

(e)

Figure 8. Effect of loading rod length on phase angle ( $\psi$ ) for three face sheet thicknesses (a) $0.5 \mathrm{~mm}$ (b) $3 \mathrm{~mm}$ and (c) $7 \mathrm{~mm},(\psi)$ vs. $\Sigma$ at (d) a $=30 \mathrm{~mm}$ and (e) a $=120 \mathrm{~mm}\left(L=300 \mathrm{~mm}, h_{c}=25.4 \mathrm{~mm}\right)$. 


\section{Case studies}

A study was conducted to investigate the mode mixity conditions for typical SCB sandwich specimens used in different industries, namely aerospace, marine and wind. Material properties selected for face sheet and core materials representative of each industry are provided in Table 4. To keep the analysis simple and devoid of any additional failure mechanisms, face sheets comprised of unidirectional (UD) fibers were considered. The geometrical parameters chosen for the analysis are also shown in Table 4. The loading rod length was kept constant at $L_{\text {rod }}=500 \mathrm{~mm}$, and a maximum crack length of $\mathrm{a}_{\max }=150$ $\mathrm{mm}$ was chosen. The minimum required intact length $\left(L_{b, \min }\right)$ was calculated using Equation (10) for each specimen. A unit load of $P=1 \mathrm{~N} / \mathrm{mm}$ was applied. The core was modeled as orthotropic and the FEmodel was solved as geometrically non-linear for all cases.

A plot of the mode mixity phase angle $(\psi)$ vs. crack length is presented in Figure 9 for all three sandwich systems presented in Table 4. Pure mode I conditions in terms of phase angle were defined to exist between $-10^{\circ} \leq \psi \leq 10^{\circ}$. A line demarcating $\psi=10^{\circ}$ shows the region in which mode I regime exists in Figure 9. For all cases considered here, short crack lengths exhibit increased mode mixity.

The aerospace specimen (Carbon/Nomex honeycomb core), with thin face sheet $\left(h_{f} \leq 0.5 \mathrm{~mm}\right)$ was observed to be in the mode I regime for the entire range of crack lengths. For face sheets with $h_{f} \geq 1 \mathrm{~mm}$, a mode I regime exists for crack length a $>20 \mathrm{~mm}$ (see Figure 9a). It was observed that phase angle for $h_{f} \geq 1.5 \mathrm{~mm}$ converged and followed the same trend at all crack lengths. The discrepancy in mode mixity for all face sheet thicknesses was small for crack length, a $\geq 90 \mathrm{~mm}$.

Results for the marine configuration (Glass/epoxy tape/ H100) are shown in Figure 9b for all face sheet thicknesses. The phase angle $(\psi)$ lies in the mode I regime at all crack lengths, but was larger for short crack lengths. The specimen with thin face sheet $\left(h_{f}=0.5 \mathrm{~mm}\right)$ exhibited the lowest phase angle at all crack lengths. For specimen with thicker face sheets $\left(h_{f} \geq 2 \mathrm{~mm}\right)$, the phase angle converged with increased crack lengths, with the exception of face sheet with $h_{f}=7 \mathrm{~mm}$.

In the case of the sandwich system used in the wind industry (Glass/epoxy - Balsa) for all face sheet thicknesses, a mode I region exists for a $>30 \mathrm{~mm}$ (see Figure 9c). For $h_{f}=0.5 \mathrm{~mm}$, the phase angle was within the mode I bounds at all crack lengths. As observed in the other cases, with increased crack lengths, the phase angle values tend to converge $\left(\sim 8^{\circ}\right)$ for $\mathrm{a} \geq 60 \mathrm{~mm}$. Note that for $\psi<0^{\circ}$, the propensity of the crack was to kink towards the face sheet. When $\psi>0^{\circ}$, the inclination of the crack was to enter into the core, especially if the core was soft. The specimen dimensions of the various test cases presented in this study were representative of each industry. In accordance with the analysis presented in this section, it was recommended not to consider the energy-release rate computed for an initial debond increment up to $30 \mathrm{~mm}$. Moreover, an initial cycle with a debond increment close to $30 \mathrm{~mm}$ aids in creating a natural crack front. 
Table 4. Typical material properties of sandwich composites used in aerospace, marine and wind industries.

\begin{tabular}{|c|c|c|c|c|}
\hline & \multicolumn{2}{|c|}{ Face sheet } & \multicolumn{2}{|c|}{ Core } \\
\hline $\begin{array}{l}\text { Aerospace } \\
\text { Carbon/epoxy/Honeycomb } \\
\left.\text { (T300/5208 carbon/epoxy [26] } \text { /Nomex Honeycomb }^{1}[27][28]\right) \\
\\
h_{c}=25.4 \mathrm{~mm} \\
L_{b, \min }=120 \mathrm{~mm} \\
\mathrm{~L}=270 \mathrm{~mm} \\
\mathrm{a}_{\max }=150 \mathrm{~mm} \\
\Sigma=1350, \alpha=0.99, \beta=0.323\end{array}$ & $\begin{array}{c}\mathrm{E}_{11}[\mathrm{GPa}] \\
\mathrm{E}_{22}[\mathrm{GPa}] \\
\mathrm{E}_{33}[\mathrm{GPa}] \\
\mathrm{G}_{12}[\mathrm{GPa}] \\
\mathrm{G}_{13}[\mathrm{GPa}] \\
\mathrm{G}_{23}[\mathrm{GPa}] \\
v_{12} \\
v_{13} \\
v_{23}\end{array}$ & $\begin{array}{c}162 \\
14.9 \\
14.9 \\
5.7 \\
5.7 \\
5.4 \\
0.283 \\
0.283 \\
0.386\end{array}$ & $\begin{array}{c}\mathrm{E}_{11}[\mathrm{MPa}] \\
\mathrm{E}_{22}[\mathrm{MPa}] \\
\mathrm{E}_{33}[\mathrm{MPa}] \\
\mathrm{G}_{12}[\mathrm{MPa}] \\
\mathrm{G}_{13}[\mathrm{MPa}] \\
\mathrm{G}_{23}[\mathrm{MPa}] \\
v_{12} \\
v_{31} \\
v_{32} \\
\text { Density }\left[\mathrm{kg} / \mathrm{m}^{3}\right] \\
\text { Cell size }[\mathrm{mm}]\end{array}$ & $\begin{array}{c}0.082 \\
0.082 \\
121.6 \\
0.092 \\
31.0 \\
19.0 \\
1.0 \\
0.40 \\
0.40 \\
32 \\
4.8\end{array}$ \\
\hline $\begin{array}{l}\text { Marine } \\
\text { (Glass/expoy tape/H100) } \\
\text { DBLT-850-E10 Quadriaxial } \\
\text { glass fiber mats }(0 / 45 / 90 /-45) / \mathrm{H} 100 \\
\text { [29][23] } \\
h_{c}=40 \mathrm{~mm} \\
L_{b, \min }=76 \mathrm{~mm} \\
\mathrm{~L}=226 \mathrm{~mm} \\
\mathrm{a}_{\max }=150 \mathrm{~mm} \\
\Sigma=138, \alpha=0.99, \beta=0.164\end{array}$ & $\begin{array}{c}\mathrm{E}_{11}[\mathrm{GPa}] \\
\mathrm{E}_{22}[\mathrm{GPa}] \\
\mathrm{E}_{33}[\mathrm{GPa}] \\
\mathrm{G}_{12}[\mathrm{GPa}] \\
\mathrm{G}_{13}[\mathrm{GPa}] \\
\mathrm{G}_{23}[\mathrm{GPa}] \\
v_{12} \\
v_{13} \\
v_{23}\end{array}$ & $\begin{array}{c}18.6 \\
18.0 \\
9.5 \\
6.1 \\
2.7 \\
2.8 \\
0.40 \\
0.37 \\
0.43\end{array}$ & $\begin{array}{c}\mathrm{E}_{\mathrm{c}}[\mathrm{MPa}] \\
\mathrm{G}_{\mathrm{c}}[\mathrm{MPa}] \\
v_{c} \\
\text { Density }\left[\mathrm{kg} / \mathrm{m}^{3}\right] \\
\text { Cell size }[\mathrm{mm}]\end{array}$ & $\begin{array}{c}135 \\
35 \\
0.40 \\
100 \\
0.45\end{array}$ \\
\hline $\begin{array}{l}\text { Wind } \\
\text { (Glass/epoxy plain weave/Balsa): } \\
\text { S2/8552 Unidirectional Glass-epoxy } \\
\text { Prepreg / } \\
\text { High density Balsa wood [30] } \\
h_{c}=30 \mathrm{~mm} \\
L_{b, \min }=104.2 \mathrm{~mm} \\
\mathrm{~L}=255 \mathrm{~mm} \\
\mathrm{a}_{\max }=150 \mathrm{~mm} \\
\Sigma=7.2, \alpha=0.75, \beta=0.212\end{array}$ & $\begin{array}{c}\mathrm{E}_{11}[\mathrm{GPa}] \\
\mathrm{E}_{22}[\mathrm{GPa}] \\
\mathrm{E}_{33}[\mathrm{GPa}] \\
\mathrm{G}_{12}[\mathrm{GPa}] \\
\mathrm{G}_{13}[\mathrm{GPa}] \\
\mathrm{G}_{23}[\mathrm{GPa}] \\
v_{12} \\
v_{13} \\
v_{23}\end{array}$ & $\begin{array}{l}14.79 \\
12.73 \\
12.73 \\
9.79 \\
4.83 \\
4.48 \\
0.278 \\
0.279 \\
0.403\end{array}$ & $\begin{array}{c}\mathrm{E}_{11}[\mathrm{MPa}] \\
\mathrm{E}_{22}[\mathrm{MPa}] \\
\mathrm{E}_{33}[\mathrm{MPa}] \\
\mathrm{G}_{12}[\mathrm{MPa}] \\
\mathrm{G}_{13}[\mathrm{MPa}] \\
\mathrm{G}_{23}[\mathrm{MPa}] \\
v_{12} \\
v_{13} \\
v_{23} \\
\text { Density }\left[\mathrm{kg} / \mathrm{m}^{3}\right]\end{array}$ & $\begin{array}{c}6620 \\
428.3 \\
98.3 \\
355.9 \\
243.8 \\
243.8 \\
0.3 \\
0.5 \\
0.23 \\
237\end{array}$ \\
\hline
\end{tabular}

${ }^{1}$ Nomex paper properties: $E_{\text {paper }}=3.13 \mathrm{GPa}, v_{\text {paper }}=0.4[31]$ and cell wall thickness $=0.057 \mathrm{~mm}$. 


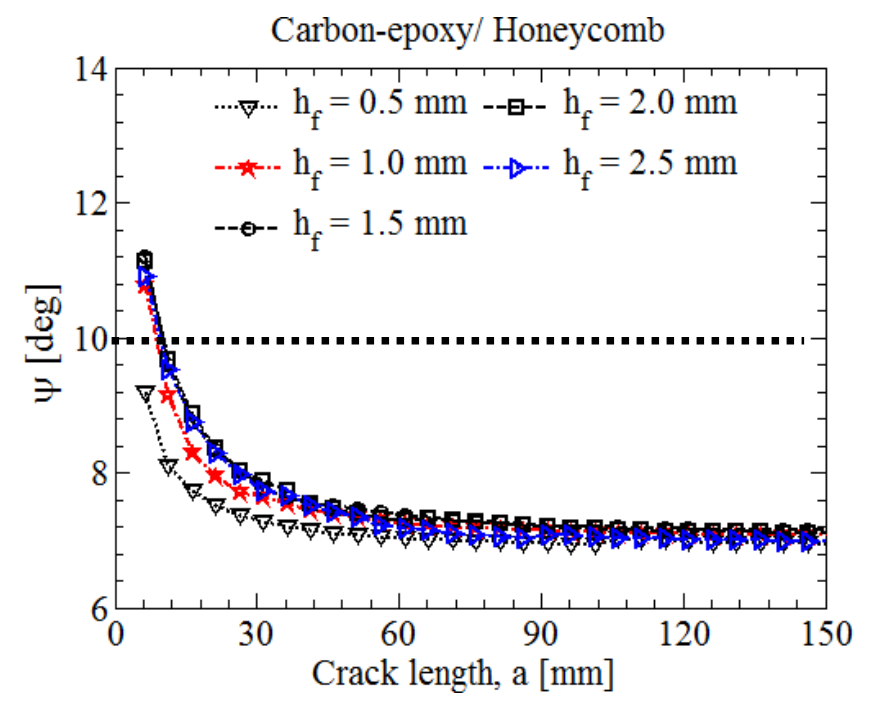

(a)

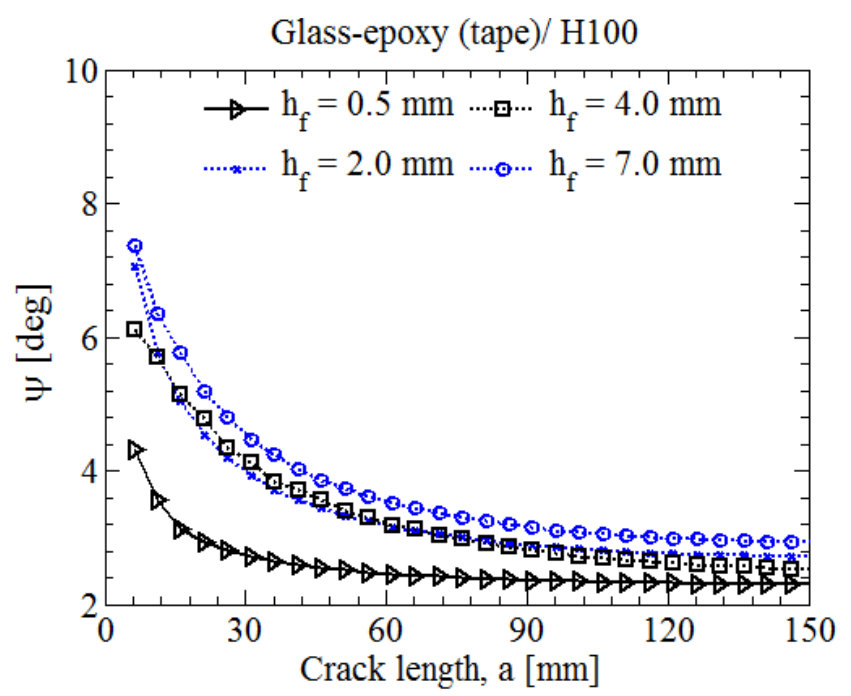

(b)

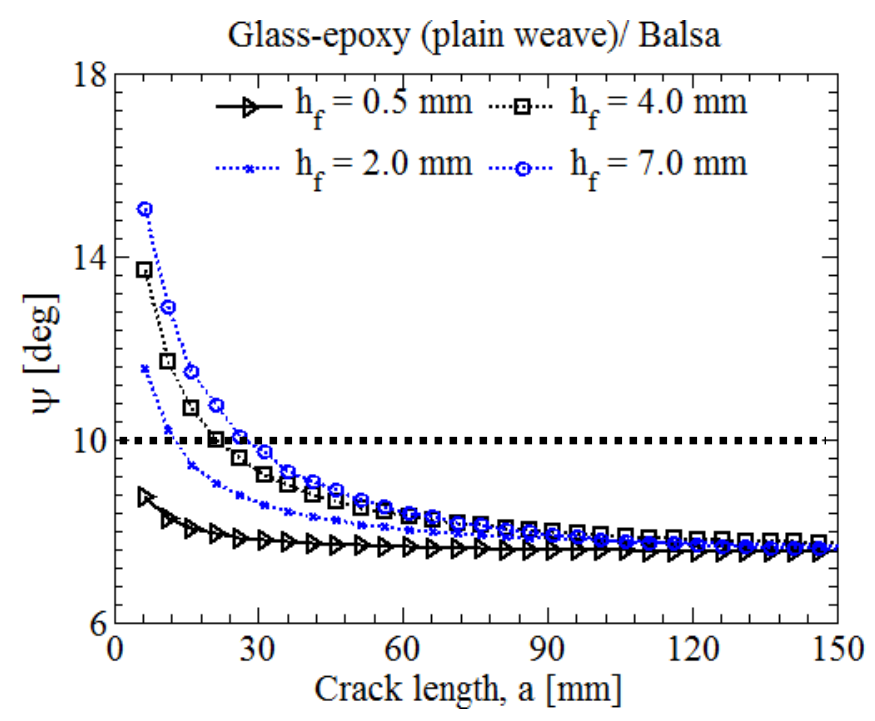

(c)

Figure 9. Mode mixity variation of SCB specimens for typical applications in (a) aerospace $(\Sigma=1350$, $\alpha=0.99)$ (b) marine $(\Sigma=138, \alpha=0.99)$ (c) wind energy $(\Sigma=7.2, \alpha=0.75)$.

\section{Energy-release rate of SCB sandwich specimen}

In previous sections, the crack tip mode mixity was investigated by applying a unit load $(P=1 \mathrm{~N} / \mathrm{mm})$ at all crack lengths in the range a $=0.5$ to $150 \mathrm{~mm}$. In a SCB specimen, the energy-release rate, $G$, invariably depends on magnitude of the applied load (see Equation 12). For a unit load at a particular crack length, different sandwich systems gave rise to various levels of energy release rate values. In order 
to study the variation of mode mixity phase angle $(\psi)$ with the applied load magnitude, an analysis was carried out by incrementally varying the load, $P$, at a given crack length.

A typical marine grade sandwich specimen was used in the analysis: E-glass epoxy tape/H100 (see Table 4 for mechanical properties). The thicknesses of face sheet and core were $h_{f}=5 \mathrm{~mm}$ and $h_{c}=25.4 \mathrm{~mm}$, respectively. The length of the specimen was $L=300 \mathrm{~mm}$, and the rod length was $L_{\text {rod }}=500 \mathrm{~mm}$. Energyrelease rate and phase angle were extracted for three different crack lengths $(\mathrm{a}=5,10$ and $25 \mathrm{~mm})$ by incrementing the load in steps. The energy-release rate, $G$, was obtained from the FE-model using the CSDE method (see Equation 6). The energy-release rate expression for the SCB specimen, in terms of the applied load $P$, was expressed as [13], [20]:

$$
G=\frac{2 P^{2} \lambda^{2}}{b k}\left[\lambda^{2} a^{2}+2 \lambda a+1\right]
$$

where $\lambda$ is defined in Equation (9). The elastic foundation modulus, $k$, was defined empirically in the literature, and three foundation modulus expressions were employed to compute the energy release rate for comparison [20], [24], [25]. The foundation modulus expressions used in this section were the same ones previously considered (see Table 3). A comparison of the normalized energy-release rate obtained using the FEA and analytical expression is presented in Figure 10. Both energy-release rate and applied load were normalized with $E_{f} \cdot h_{f}$. The various foundation modulus expressions were also provided in the plot (see inset of Figure 10).

For the short crack length $(\mathrm{a}=5 \mathrm{~mm})$, the energy-release rate, $G$, obtained using Quispitupa et al. [25] match closely with results from FEA at lower loads (see Figure 10a). Significant deviation between FEA and analytical results is observed when the load increased, which was attributed to the large-scale deformation of the face sheet. For a longer crack length $(\mathrm{a}=25 \mathrm{~mm})$, the deviation observed between FEA and analytically obtained $G$ using the $k$ proposed by Quispitupa et al. [25] was also small (see Figure 10b). The other two modulus expressions considered here [20], [24], showed large deviation from FE results for both the crack lengths considered here (see Figure 10).

The mode mixity phase angle $(\psi)$ at various load levels corresponding to each crack length is provided in Figure 11 for the E-glass/H100 sandwich system. For a short crack length $(\mathrm{a}=5 \mathrm{~mm})$, the phase angle, $\psi$, changed from $2.4^{\circ}$ to $1.1^{\circ}$, whereas for $\mathrm{a}=25 \mathrm{~mm}, \psi$ decreased from $2.8^{\circ}$ to $0.2^{\circ}$. In addition, $\psi$ decreased linearly with increased load magnitude. The change in mode mixity with load magnitude is in the range of $2^{\circ}$ for the various crack length cases considered. However, the energy-release rate depended on the applied loading. Therefore, it was recommended to employ the area method to deduce the energy released when the specimen undergoes large-scale deformation during testing. 


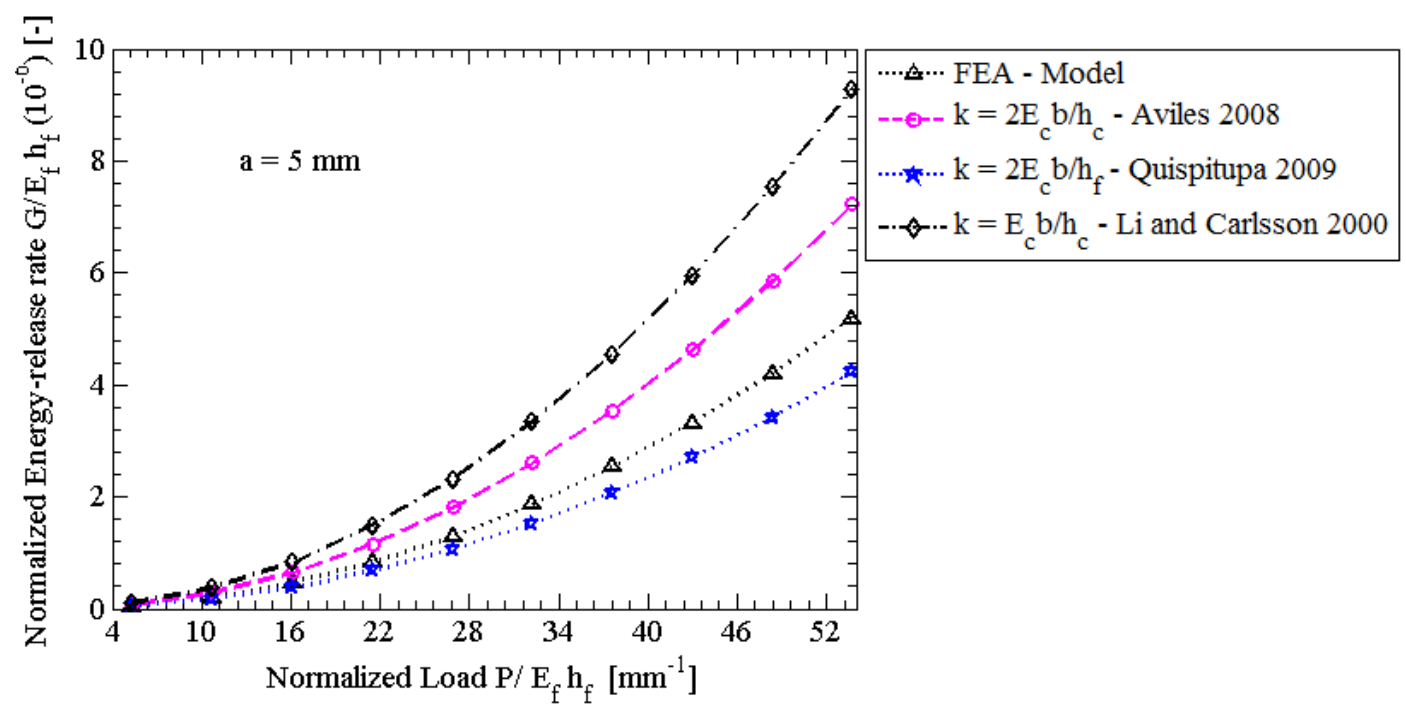

(a)

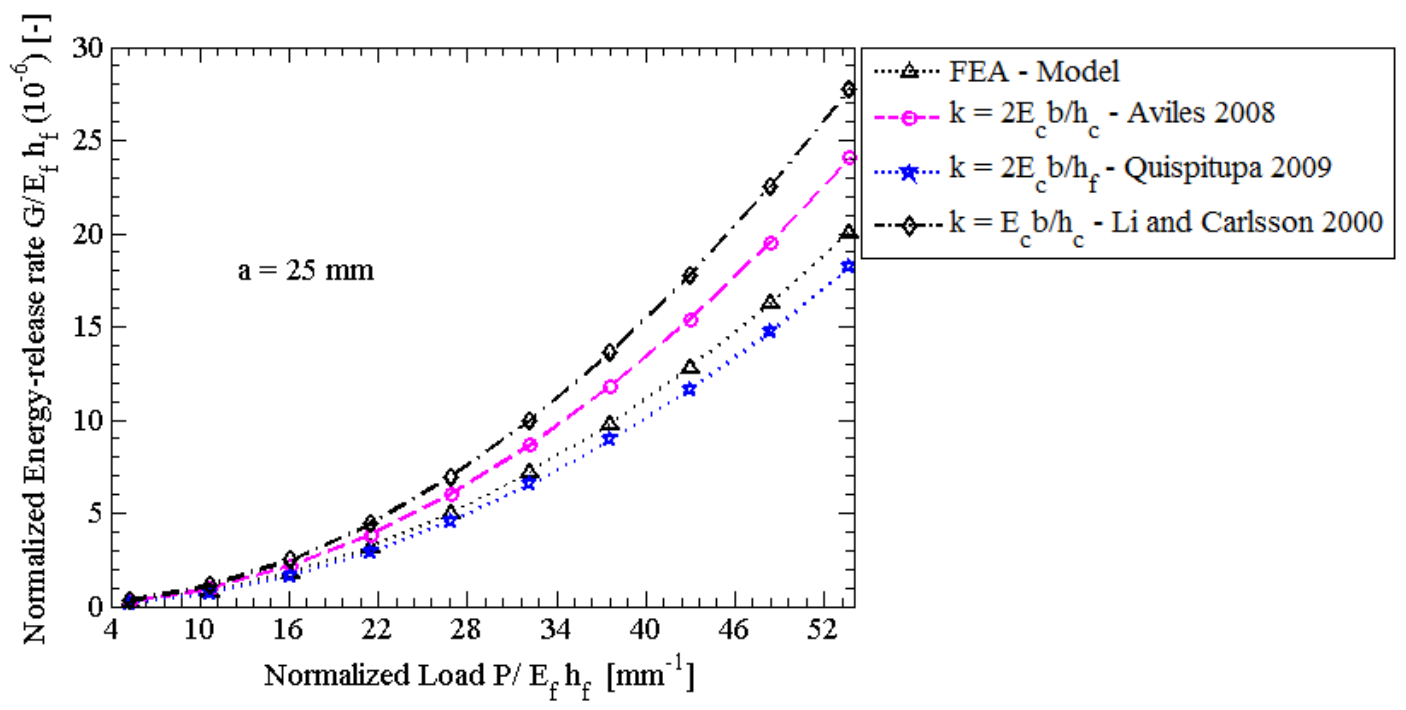

(b)

Figure 10. Comparison of energy-release rate obtained from finite-element results and from analytical approach for E-glass/H100 SCB sandwich specimen $\left(L=300 \mathrm{~mm}, L_{\text {rod }}=500 \mathrm{~mm}\right)$, crack length (a) $\mathrm{a}=5 \mathrm{~mm}$ (b) $\mathrm{a}=25 \mathrm{~mm}$. 


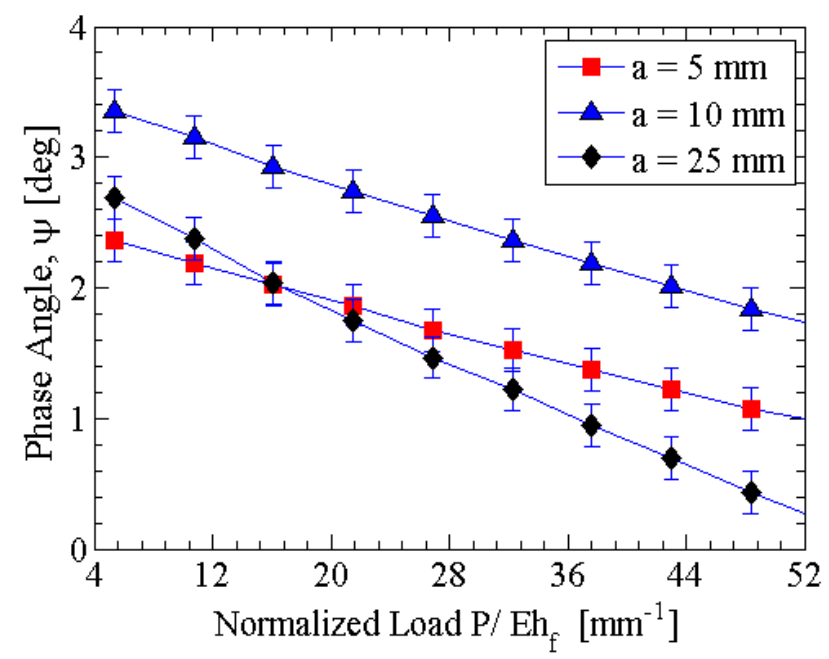

Figure 11. Phase angle vs. applied load for E-glass/H100 SCB specimen at crack lengths, a = 5, 10 and $25 \mathrm{~mm}$.

\section{SCB sandwich specimen reinforced with stiff layers (doublers)}

Fracture testing of SCB specimens with thin face sheets invariably causes excessive deformation [32]. Such large deformations of the face sheet make it unviable to employ data reduction methods such as the modified beam theory (MBT) and the compliance calibration method, as the measured compliance $(C=$ $\delta / P)$ vs. crack length yields a non-linear trend. Moreover, a large lift-off of the face sheet leads to membrane forces, causing matrix cracking/damage. Any additional damage to the specimen is undesirable as the load measured through the machine load cell contains a component of force that caused the undesired damage. The additional force affects the fracture toughness data of face/core interface.

One way to circumvent damage in the face sheet, and thereby reduce the excessive lift-off was by attaching a stiff layer atop the upper face sheet. Such stiff reinforcement layers, referred to as "doublers", were bonded to specimens with thin, compliant face sheets [33]. However, addition of a doubler layer on the upper face sheet influences the mode mixity phase angle $(\psi)$. The extent of influence depends on the stiffness and thickness of the doubler layer. A numerical study using the previously presented FE model was undertaken in which the model was expanded by attaching a doubler layer on the top face sheet (see Figure 12). The investigation was carried out for SCB specimens with face sheet thickness less than 1 $\mathrm{mm}$. Note that irrespective of the addition of a doubler layer on the face sheet, the mode mixity phase angle must remain within the earlier assumed bounds $\left(-10^{\circ} \leq \psi \leq 10^{\circ}\right)$ to be in the mode I regime. 


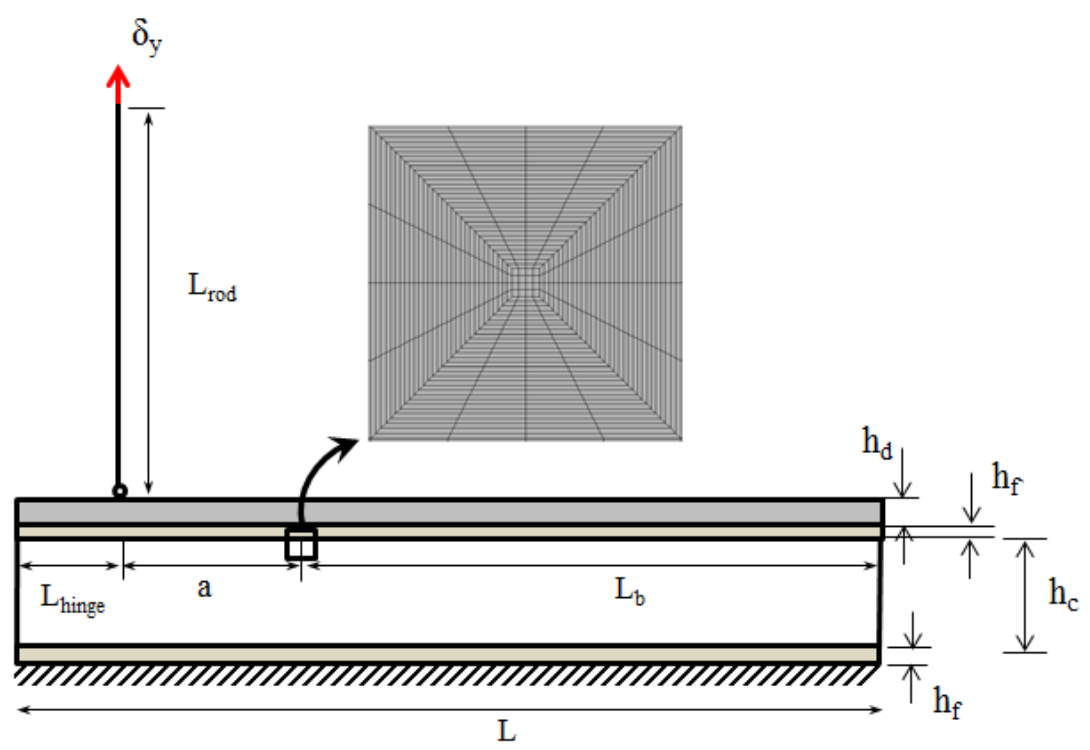

Figure 12. FE-model of a sandwich SCB specimen reinforced with a doubler layer, $h_{d}$.

A previous study of a similar nature was conducted on the Tilted Sandwich Debond (TSD) specimen [34] and the influence of a stiffener layer on the phase angle was reported for various tilt angles. To benchmark and extend the analysis performed in [34] to a SCB sandwich specimen, similar face/core sandwich systems were used. The mechanical properties of face sheet, core and doubler layer are provided in Table 5. The minimum length of intact portion was estimated using Equation (10) with $k=E_{c} b / h_{c}$ [20] and was kept constant throughout the analysis $\left(L_{b, \min }=32.7 \mathrm{~mm}\right)$. Throughout this section, the total length of the specimen and the loading rod length were fixed at $L=200 \mathrm{~mm}$ and $L_{\text {rod }}=$ $500 \mathrm{~mm}$, respectively. A unit load was applied at each crack length until $\mathrm{a}_{\max }=150 \mathrm{~mm}$, and the solution was obtained using the geometrical non-linear solver.

Table 5. Mechanical properties of face sheet, core and doubler layer.

\begin{tabular}{|c|c|c|c|c|c|c|}
\hline \multicolumn{3}{|c|}{ Face sheet } & \multicolumn{2}{c|}{$\begin{array}{c}\text { Core } \\
\text { (PVC H100) }\end{array}$} & \multicolumn{2}{c|}{$\begin{array}{c}\text { Doubler Layer } \\
\text { (Steel) }\end{array}$} \\
\cline { 1 - 3 } & GFRP & CFRP & $\mathrm{E}_{\mathrm{c}}[\mathrm{MPa}]$ & 135 & $\mathrm{E}_{\mathrm{d}}[\mathrm{GPa}]$ & 210 \\
$\mathrm{E}_{11}[\mathrm{GPa}]$ & 20.6 & 44.0 & $\mathrm{G}_{\mathrm{c}}[\mathrm{MPa}]$ & 35 & $v_{d}$ & 0.30 \\
$\mathrm{E}_{22}[\mathrm{GPa}]$ & 20.6 & 44.0 & $v_{c}$ & 0.40 & & \\
$\mathrm{E}_{33}[\mathrm{GPa}]$ & 9.90 & 9.90 & & & \\
$\mathrm{G}_{12}[\mathrm{GPa}]$ & 3.10 & 6.62 & Density $\left[\mathrm{kg} / \mathrm{m}^{3}\right]$ & 100 & & \\
$\mathrm{G}_{13}[\mathrm{GPa}]$ & 2.90 & 6.20 & Cell size $[\mathrm{mm}]$ & 0.45 & & \\
$\mathrm{G}_{23}[\mathrm{GPa}]$ & 2.90 & 6.20 & & & & \\
$v_{12}$ & 0.12 & 0.12 & & & & \\
$v_{13}$ & 0.37 & 0.37 & & & & \\
$v_{23}$ & 0.37 & 0.37 & & & & \\
\hline
\end{tabular}




\section{Reinforced SCB: Effect of doubler layer thickness $\left(h_{d}\right)$}

The influence of doubler layer thickness on the mode mixity phase angle $(\psi)$ was investigated by varying the steel doubler layer thickness $h_{d}$, from 2 to $12 \mathrm{~mm}$. Core and face sheet thickness of GFRP/H100 sandwich were held constant at $h_{c}=25 \mathrm{~mm}$ and $h_{f}=2 \mathrm{~mm}$ respectively. A plot of $\psi$ vs. crack length for various doubler layer thicknesses is shown in Figure 13. For comparison, the phase angle $(\psi)$ variation of an un-reinforced specimen $\left(h_{d}=0 \mathrm{~mm}\right)$ was also provided. It was noted that the phase angle deviates more toward the mixed-mode regime as the doubler thickness $\left(h_{d}\right)$ increases. For the case of an unreinforced SCB specimen, the mode mixity was observed to remain just above the mode I region (see Figure 13). Hence for the particular case of GFRP/H100 sandwich system considered here, mode I regime cannot be achieved by addition of doubler layers

The phase angle $(\psi)$ for specimens reinforced with doublers was observed to gradually increase at higher crack lengths in Figure 13. The departure occurred at various crack lengths depending on the doubler layer thickness. The shift in $\psi$ indicates the insufficient intact length $\left(L_{b}\right)$ confirmed in an earlier section. Therefore, Equation (10) was modified such that the intact portion was calculated taking into account the flexural modulus of the entire upper beam consisting of both doubler and face sheet. An expression for the minimum intact length $\left(L_{b, \min }\right)$ which takes into account a doubler layer attached to top face sheet is provided in Appendix A.

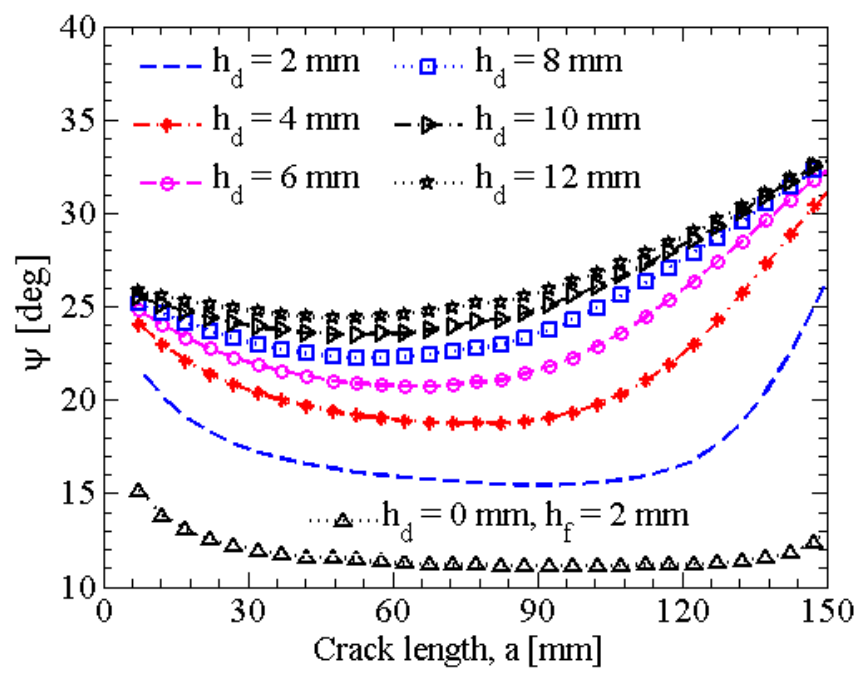

Figure 13. Phase angle $(\psi)$ vs. crack length (a) for a GFRP/H100 SCB specimen reinforced with a doubler layer $\left(h_{f}=2 \mathrm{~mm}, h_{c}=25 \mathrm{~mm}\right)$. 


\section{Reinforced SCB: Effect of face sheet modulus $\left(E_{f}\right)$}

The effect of face sheet modulus $\left(E_{f}\right)$ on the phase angle $(\psi)$ is presented in this section. Two different face sheets (GFRP and CFRP) described in Table 5 were utilized with H100 core. The steel doubler layer thickness was varied from 2 to $12 \mathrm{~mm}$. Face sheet and core thickness were held constant at $h_{f}=2 \mathrm{~mm}$ and $h_{c}=25 \mathrm{~mm}$. The specimen was loaded with a unit load as in previous analyses until $\mathrm{a}_{\max }=150 \mathrm{~mm}$.

A plot of $\psi$ vs. crack length for the two sandwich systems is provided in Figure 14. The phase angle $(\psi)$ increased with increasing in doubler thickness for both sandwich systems considered. It is observed that $\psi$ tends to converge at large values of $h_{d}$ for both CFRP/H100 and GFRP/H100 cases. The mode I regime characterized within $-10^{\circ} \leq \psi \leq 10^{\circ}$ was not observed for any case. A clear indication of insufficient intact portion length was also observed in the plot where an increase in $\psi$ was observed at increasing crack length.

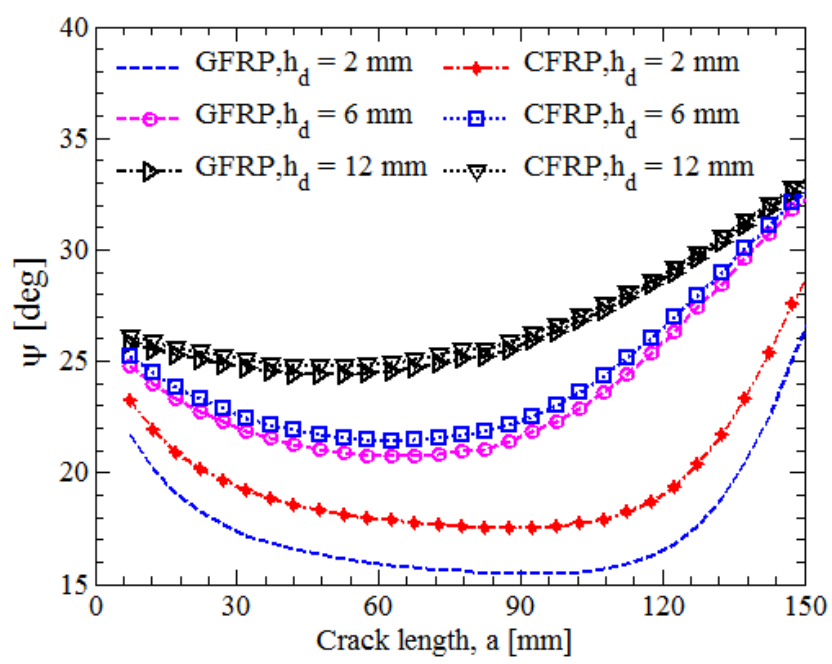

Figure 14. Phase angle $(\psi)$ computed for SCB specimens; GFRP/H100 and CFRP/H100 $\left(h_{f}=2 \mathrm{~mm}, h_{c}\right.$ $=25 \mathrm{~mm}$ ) with stiffener layer thickness, $h_{d}=2-12 \mathrm{~mm}$.

\section{Reinforced SCB: Effect of core thickness ( $\left.h_{c}\right)$}

The influence of core thickness $\left(h_{c}\right)$ on the phase angle $(\psi)$ in a reinforced SCB sandwich specimen is presented in this section. Three core thicknesses were used for this analysis; $h_{c}=10,25$ and $40 \mathrm{~mm}$. A GFRP/H100 sandwich specimen with a face sheet thickness $h_{f}=2 \mathrm{~mm}$ was considered. Two steel doubler layer thicknesses, $h_{d}=2$ and $12 \mathrm{~mm}$, were considered for the three core thickness cases. A plot of $\psi$ vs. crack length is provided in Figure 15 for the two doubler layer cases. For comparison, the phase angle obtained for a GFRP/H100 specimen without any doubler layer $\left(h_{d}=0 \mathrm{~mm}\right)$ is also presented in Figure 15 for a core thickness, $h_{c}=25 \mathrm{~mm}$. 
It was observed that, for a thick core $\left(h_{c}=40 \mathrm{~mm}\right)$, regardless of the doubler layer thickness, $\psi$ remains positive and deviates away from the mode I condition. In the crack length range $30<\mathrm{a}<120 \mathrm{~mm}$, the phase angle for $h_{d}=12 \mathrm{~mm}$ and $h_{c}=10 \mathrm{~mm}$ was equal to the case with $h_{d}=0 \mathrm{~mm}$ and $h_{c}=25 \mathrm{~mm}$ (see Figure 15b). None of the investigated configurations involving thin and thick cores satisfied the mode I criterion. In addition, insufficient intact length was more evident in the case with a thick doubler layer (Figure 15b), where $\psi$ was observed to deviate away from the plateau for all the three core thicknesses. From the analysis undertaken here, use of a doubler layer was not recommended, as the phase angle was observed to increase toward positive region leading to significant deviation from the mode I condition. For both thin and thick doubler layers, the crack will kink into the core for all cases of $\psi>0$.

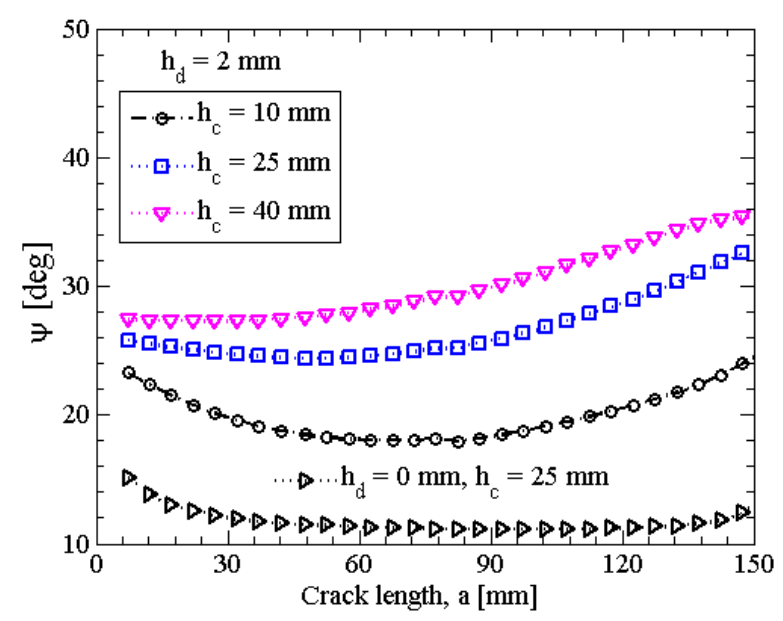

(a)

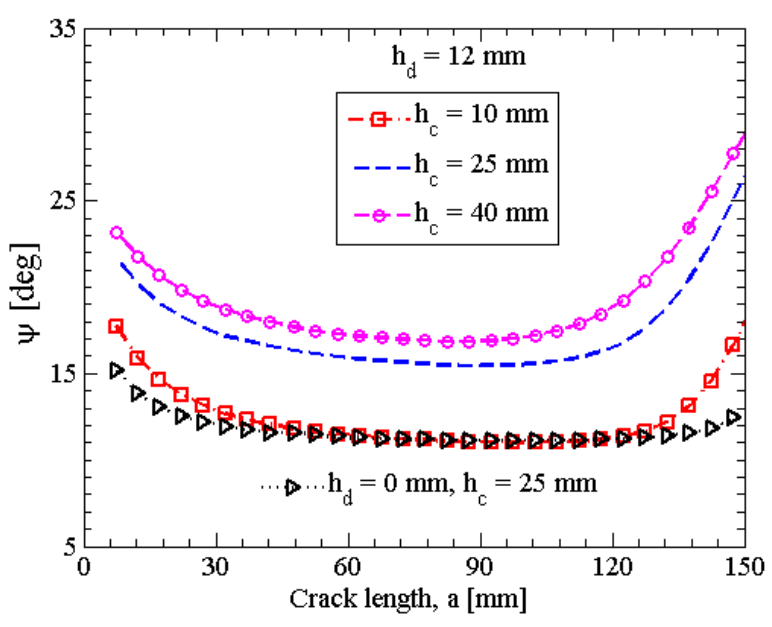

(b)

Figure 15. Phase angle ( $\psi$ ) vs. crack length (a) various core thicknesses for GFRP/H100 SCB specimen with constant $h_{f}=2 \mathrm{~mm}$ (a) $h_{d}=2 \mathrm{~mm}$ (b) $h_{d}=12 \mathrm{~mm}$.

\section{Reinforced SCB specimen: Effect of doubler modulus $\left(E_{d}\right)$}

To investigate the effect of doubler modulus $\left(E_{d}\right)$ on the mode mixity, a CFRP/H100 sandwich system with three doubler materials was studied. The core, face sheet and doubler layer thickness were held constant: $h_{c}=25 \mathrm{~mm}, h_{f}=2 \mathrm{~mm}$ and $h_{d}=2 \mathrm{~mm}$. The total length of the specimen and the rod length were kept as previous, $L=200 \mathrm{~mm}$ and $L_{\text {rod }}=500 \mathrm{~mm}$. The three doubler layer materials chosen in this section were: E-glass/epoxy, aluminum and steel with stiffness, $E_{d}=20,70$ and $210 \mathrm{GPa}$, respectively.

A plot of $\psi$ vs. crack length is provided in Figure 16. The $\psi$ values for the SCB specimen reinforced with stiffer steel were slightly larger than the ones reinforced with GFRP and aluminum. As previously, $\psi$ deviated from the plateau for crack length, a $>100 \mathrm{~mm}$, indicating an inaccurate intact length estimation. In general, the stiffness of the doubler layer was seen to have less influence on the phase angle. Therefore, 
the phase angle was predominantly influenced by a combination of stiffness and thickness of both doubler layer and face sheet.

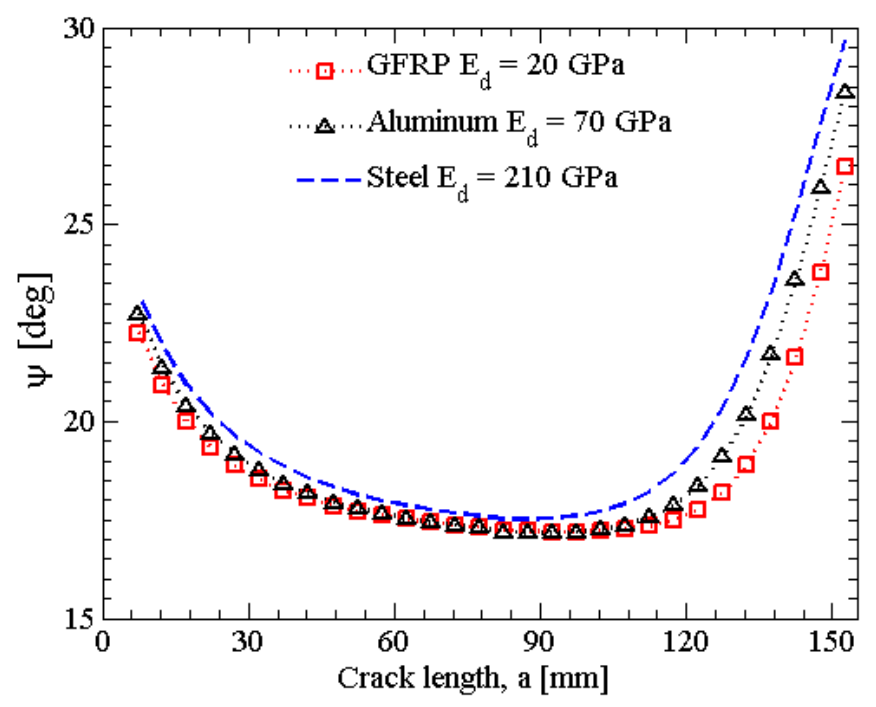

Figure 16. Phase angle $(\psi)$ vs. crack length of reinforced CFRP/H100 SCB sandwich specimen with doubler layer stiffnesses; $E_{d}=20,70$ and $210 \mathrm{GPa}\left(h_{d}=2 \mathrm{~mm}, h_{f}=2 \mathrm{~mm}\right.$ and $\left.h_{c}=25 \mathrm{~mm}\right)$.

\section{Conclusions}

The sandwich SCB specimen was investigated from a local mode mixity perspective using the numerical Crack Surface Displacement Extrapolation (CSDE) method by varying both geometrical and material parameters. The parametric study was carried out using hypothetical SCB sandwich specimens, and the mode I regime was assumed in the range $-10^{\circ} \leq \psi \leq 10^{\circ}$.

- For a constant face sheet thickness $\left(h_{f}\right)$, stiffer face sheets led to increasingly positive values of $\psi$ which deviate away from the mode I condition.

- Specimens with thick core and thick face sheets yielded increased phase angle, whereas specimens with thin core and thick face sheets yielded lower phase angles.

- Depending on how stiff the core was, the face sheet thickness $\left(h_{f}\right)$ along with the ratio of face sheet and core moduli $\left(\Sigma=E_{f} / E_{c}\right)$ influence $\psi$. For constant core properties, the specimens with thinner face sheets exhibited lower values of $\psi$. In addition, core Poisson's ratio $\left(v_{c}\right)$ was shown to influence the mode mixity. Crack propagation in a core with higher Poisson's ratio $\left(v_{c}\right)$ was observed to lie close to mode I regime.

- The intact portion length was seen to influence the phase angle $(\psi)$, especially at large crack lengths. In general, thinner face sheets require shorter intact portions. Various equations for 
elastic foundation modulus, $k$, were used to determine the minimum intact portion length and the expression provided by $\mathrm{Li}$ et al. [20] was found to provide a valid estimate.

- For the considered sandwich construction, modeled results showed significant deviation from mode I regime with loading rods shorter than $500 \mathrm{~mm}$. Therefore, a loading rod length in terms of the length of the specimen was recommended as: $L_{\text {rod }} \geq 1.70 \mathrm{~L}$.

- A case study involving typical sandwich systems used in three different industries aerospace, marine and wind energy was presented. The case study demonstrated a mode I window $\left(-10^{\circ} \leq\right.$ $\psi \leq 10^{\circ}$ ) which exists over various face sheet thickness and crack lengths for the investigated SCB specimen configurations. It was recommended to disregard the initial cycle associated with a debond increment of $\sim 30 \mathrm{~mm}$ for the energy-release rate estimation. In addition, an initial cycle enabled creation of a natural crack front.

- For a constant crack length, it was observed that the fluctuation of mode mixity phase angle at various load magnitudes was negligible $\left(\sim 1.5^{\circ}\right.$ for $\mathrm{a}=5 \mathrm{~mm}$ and $3.0^{\circ}$ for $\left.\mathrm{a}=25 \mathrm{~mm}\right)$. The area method was recommended to deduce the energy released for non-linear specimen response.

- Reinforcing the SCB specimen with a stiff doubler layer was observed to shift the mode condition away from mode I, which qualitatively agrees with the literature. The intact specimen length expression was modified to account for a reinforced SCB specimen.

The parametric analysis was performed in this paper using both hypothetical as well as real sandwich systems. It was found that the existing sizing method yielded specimen configurations which remain in the mode I regime. Furthermore, despite conforming to the sizing requirements, a certain class of specimens was also found to deviate away from the mode I bounds. Also, specimens which did not adhere to the sizing standard were also observed to satisfy the mode I conditions. Therefore, in the absence of a closed form expression to determine the mode mixity phase angle $(\psi)$ for a SCB sandwich specimen, it was advised to proceed with caution with regard to the selection of specimen configuration. It is highly recommended to perform a limited series of mode mixity analyses prior to fracture testing.

\section{APPENDIX A: Minimum intact length of a reinforced SCB specimen}

The expression to calculate intact portion length $\left(L_{b}\right)$ was modified to accommodate a reinforced SCB sandwich specimen and is presented in this section. Equation 10 provides an estimate of $L_{b}$ based on the parameter $\lambda$, which indicates the ratio of stiffness of the elastic foundation to the bending stiffness of the upper beam. Reinforcing the upper face sheet by addition of a stiff layer changes the flexural modulus of the beam. Hence, $\lambda$ should be modified to account for the reinforced beam. The effective modulus of the face sheet and doubler layer (see Figure 12) can be expressed as [35]:

$$
E_{x, f}^{*}=\frac{12}{d_{11} h_{D F}^{3}}
$$

where $h_{D F}=h_{f}+h_{d}$ and $d_{11}$ is the inverse component of the $D$-matrix given by: 


$$
D=\frac{1}{3} \sum_{k=1}^{n} \bar{E}_{k}\left(\mathrm{y}_{k}^{3}-\mathrm{y}_{k-1}^{3}\right)
$$

where $y_{k}$ is the $y$-coordinate of the interface between ply $k$ and $k-1$. Now, the parameter $\lambda$ is modified as:

$$
\lambda^{*}=\left[\frac{3 k}{E_{x, f}^{*} h_{f}^{3} b}\right]^{1 / 4}
$$

Therefore the new condition for minimum support length for a reinforced SCB specimen can be written as: $\lambda * L_{b, \min } \geq 2.7$.

\section{Acknowledgments}

The financial support from the Danish Centre for Composite Structures and Materials (DCCSM) funded by the Danish Council for Strategic Research within Sustainable Energy and Environment (Grant: 09067212) is gratefully acknowledged. Furthermore, the support from Kaj \& Hermilla Ostenfeld's Foundation for the first author's research stay at the NASA Langley Research Center is highly appreciated. The third author's research has been supported by the Federal Aviation Administration (FAA). Funding through the Aviation Research Grants Program, Research Grant Number 16-G-006 is gratefully acknowledged.

\section{References}

[1] "Loss of Rudder, Airbus 310-308, Air Transat Flight 961," Aviation Investigation Report A05F0047. Transportation Safety Board of Canada, Gatineau, Canada, 2007.

[2] Air Accident Investigation Branch, “AAIB Bulletin 8/92 Ref: EW/A92/5/1,” UK, 1992.

[3] Air Accident Investigation Branch, “AAIB Bulletin 2/95 Ref: EW/C94/8/3,” UK, 1995.

[4] Air Accident Investigation Branch, “AAIB Bulletin 10/96 Ref: EW/C96/6/6,” UK, 1996.

[5] M. Rinker, R. Krueger, and J. Ratcliffe, "Analysis of an Aircraft Honeycomb Sandwich Panel with Circular Face Sheet/Core Disbond Subjected to Ground-Air Pressurization," NASA Tech. Rep. CR-2013-217974, 2013.

[6] R. Goetz, R. S. Ryan, and A. F. Whitaker, "Final report of the X-33 liquid hydrogen tank test investigation team,” Marshall Sp. Flight Center, Huntsville, AL, 2000.

[7] E. H. Glaessgen, J. R. Reeder, D. W. Sleight, J. T. Wang, I. S. Raju, and C. E. Harris, “Debonding 
Failure of Sandwich-Composite Cryogenic Fuel Tank with Internal Core Pressure," J. Spacecr. Rockets, vol. 42, no. 4, pp. 613-627, 2005.

[8] C. Weaver, "Evaluation of Mode I Fracture Mechanics Test Methods For Sandwich Composites," M.Sc Thesis, University of Utah, Salt Lake City, UT, 2009.

[9] R. E. Fields and R. . Zarda, "Analysis and Test Methodology for Fracture Mechanics of Unbonded Sandwich Structures,” Martin Maerietta Task Report, EDF No. MMO TKR 10722739-001, 1994.

[10] W. J. Cantwell and P. Davies, "A test technique for assessing core-skin adhesion in composite sandwich structures,” J. Mater. Sci. Lett., vol. 13, pp. 203-205, 1994.

[11] K. Shivakumar, H. Chen, and S. A. Smith, "An Evaluation of Data Reduction Methods for Opening Mode Fracture Toughness of Sandwich Panels," J. Sandw. Struct. Mater., vol. 7, no. 1, pp. 77-90, 2005.

[12] J. W. Hutchinson and Z. Suo, "Mixed Mode Cracking in Layered Materials," Adv. Appl. Mech., vol. 29, pp. 63-191, 1991.

[13] J. G. Ratcliffe and J. R. Reeder, "Sizing a single cantilever beam specimen for characterizing facesheet-core debonding in sandwich structure," J. Compos. Mater., vol. 45, no. 25, pp. 26692684, 2011.

[14] M. F. Kanninen, "An augmented double cantilever beam model for studying crack propagation and arrest," Int. J. Fract., vol. 9, no. 1, pp. 83-92.

[15] C. Berggreen, B. C. Simonsen, and A. K. K. Borum, "Experimental and Numerical Study of Interface Crack Propagation in Foam-cored Sandwich Beams," J. Compos. Mater., vol. 41, no. 4, 2007.

[16] “ANSYS Mechanical User’s Guide.” ANSYS, Inc., Southpointe, PA, 2015.

[17] C. Berggreen, "Damage Tolerance of Debonded Sandwich Structures," Technical University of Denmark, 2004.

[18] J. Dundurs, "Discussion: 'Edge-Bonded Dissimilar Orthogonal Elastic Wedges Under Normal and Shear Loading' (Bogy, D. B., 1968, ASME J. Appl. Mech., 35, pp. 460-466)," J. Appl. Mech., vol. 36, no. 3, p. 650, 1969.

[19] M.-Y. He and J. W. Hutchinson, "Kinking of a Crack Out of an Interface," J. Appl. Mech., vol. 56, no. 2, p. 270, Jun. 1989.

[20] X. Li and L. A. Carlsson, "Elastic Foundation Analysis of Tilted Sandwich Debond (TSD) Specimen," J. Sandw. Struct. Mater., vol. 2, no. 1, pp. 3-32, 2000.

[21] S. Li, J. Wang, and M. D. Thouless, "The effects of shear on delamination in layered materials," J. Mech. Phys. Solids, vol. 52, no. 1, pp. 193-214, 2004.

[22] X. Li and L. A. Carlsson, “The Tilted Sandwich Debond (TSD) Specimen for Face/Core Interface 
Fracture Characterization," J. Sandw. Struct. Mater., vol. 1, no. 1, pp. 60-75, Jan. 1999.

[23] “Divinycell H Technical Data.” DIAB Group, Laholm, Sweden, 2016.

[24] F. Avilés and L. A. Carlsson, "Analysis of the sandwich DCB specimen for debond characterization,” Eng. Fract. Mech., vol. 75, no. 2, pp. 153-168, 2008.

[25] A. Quispitupa, C. Berggreen, and L. A. Carlsson, "On the analysis of a mixed mode bending sandwich specimen for debond fracture characterization," Eng. Fract. Mech., vol. 76, no. 4, pp. 594-613, 2009.

[26] N. K. Naik, S. I. Tiwari, and R. S. Kumar, "An analytical model for compressive strength of plain weave fabric composites," Compos. Sci. Technol., vol. 63, no. 5, pp. 609-625, 2003.

[27] Hexcel, "HexWeb Honeycomb Sandwich Design Technology,” Duxford, UK, 2000.

[28] S. Malek and L. Gibson, "Effective elastic properties of periodic hexagonal honeycombs," Mech. Mater., vol. 91, pp. 226-240, 2015.

[29] M. Manca, C. Berggreen, L. A. Carlsson, and P. Bortolotti, "Fatigue characterization of Poly Vinyl Chloride (PVC) foam core sandwich composite using the G-control method," J. Sandw. Struct. Mater., vol. 18, no. 3, pp. 374-394, 2016.

[30] A. Da Silva and S. Kyriakides, "Compressive response and failure of balsa wood," Int. J. Solids Struct., vol. 44, no. 25-26, pp. 8685-8717, 2007.

[31] C. C. Foo, G. B. Chai, and L. K. Seah, "Mechanical properties of Nomex material and Nomex honeycomb structure," Compos. Struct., vol. 80, no. 4, pp. 588-594, 2007.

[32] M. Rinker, J. G. Ratcliffe, D. O. Adams, and R. Krueger, "Characterizing Facesheet/Core Disbonding in Honeycomb Core Sandwich Structure," NASA Tech. Rep. CR-2013-217959, 2013.

[33] J. R. Reeder, K. Demarco, and K. S. Whitley, "The use of doubler reinforcement in delamination toughness testing," Compos. Part A Appl. Sci. Manuf., vol. 35, no. 11, pp. 1337-1344, 2004.

[34] C. Berggreen and L. A. Carlsson, "A Modified TSD Specimen for Fracture Toughness Characterization - Fracture Mechanics Analysis and Design," J. Compos. Mater., vol. 44, no. 15, pp. 1893-1912, 2010.

[35] L. A. Carlsson, D. F. Adams, and R. B. Pipes, Experimental Characterization of Advanced Composite Materials, 4th ed. Boca Raton, FL: CRC Press, 2008. 